\title{
Nonstationary Random Vibration Performance of Train-Bridge Coupling System with Vertical Track Irregularity
}

\author{
Xiaozhen Li, ${ }^{1}$ Yan Zhu, ${ }^{1,2}$ and Zhibin Jin ${ }^{1}$ \\ ${ }^{1}$ School of Civil Engineering, Southwest Jiaotong University, Chengdu 610031, China \\ ${ }^{2}$ School of Civil and Environmental Engineering, The University of New South Wales, Sydney, NSW 2052, Australia \\ Correspondence should be addressed to Yan Zhu; zhuyan@home.swjtu.edu.cn
}

Received 6 August 2015; Revised 2 October 2015; Accepted 8 October 2015

Academic Editor: Vadim V. Silberschmidt

Copyright (C) 2016 Xiaozhen Li et al. This is an open access article distributed under the Creative Commons Attribution License, which permits unrestricted use, distribution, and reproduction in any medium, provided the original work is properly cited.

\begin{abstract}
In order to study the random vibration performance of trains running on continuous beam bridge with vertical track irregularity, a time-domain framework of random analysis on train-bridge coupling system is established. The vertical rail irregularity is regarded as a random process. A multibody mass-spring-damper model is employed to represent a moving railway car and the bridge system is simulated by finite elements. By introducing the pseudo excitation algorithm into the train-bridge interaction dynamic system, expressions of the mean value, standard deviation, and power spectral density of the nonstationary random dynamic responses of bridge and vehicles are derived. Monte-Carlo simulations are implemented to validate the presented method. A comprehensive analysis of the train-bridge coupling system with vertical track irregularity is conducted focusing on the effect of the randomness of the vertical rail irregularity on the dynamic behavior of the running train and the three-span continuous concrete bridge. Moreover, stochastic characteristics of the indicator for assessing the safety and the riding quality of the railway cars running on continuous beam bridge are carried out, which may be a useful reference in the dynamic design of the bridge.
\end{abstract}

\section{Introduction}

The passage of moving trains leads to the dynamic amplification of a bridge; meanwhile, the motion of a bridge deck affects the kinetic characteristic of trains. The study of trainbridge coupling system commenced from the mid-19th century [1]. After that, a considerable number of investigations have been conducted on the dynamic behaviour of bridges and trains [2-15]. The majority of the literature has been devoted to the analysis of the bridge and trains vibrations when the system is subjected to deterministic loads. In conventional dynamic analysis of train-bridge coupling system, a few samples of the rail irregularity are adopted which are obtained from some transformation by use of the power spectral density (PSD) of the track irregularity. Strictly speaking, most obtained results may be sample values. Therefore, the rail irregularity, being regarded as one kind of excitation of a train-bridge coupling system, is essentially a random process and its effects on the dynamic performance of the trainbridge coupling system should be extensively investigated.
The key issue for determining the statistical characteristics of random dynamic responses of the railway bridge system, when high-speed trains are passing through, is the complexity of the coupling system. For instance, nonlinearity exists at the contacts between the wheels and the rail, and the implementation of the theories of nonstationary random vibrations to the coupling system is difficult. A few researchers [16-18] have attempted to investigate random vibration responses of the bridge using the so-called moving load model. However, without the train model, random vibration responses of the train and the interactions between the bridge and the train cannot be developed.

Monte-Carlo method has been adopted in random dynamic analysis of the train-bridge coupling system. Using Monte-Carlo simulations, many samples of the track irregularity are obtained and then analyses according to different parameters of bridges and trains are performed $[19,20]$. Xia and Zhang selected 20 samples of the rail irregularity, and then the kinetic properties of a single span box beam and the vehicles were obtained by using the samples as 


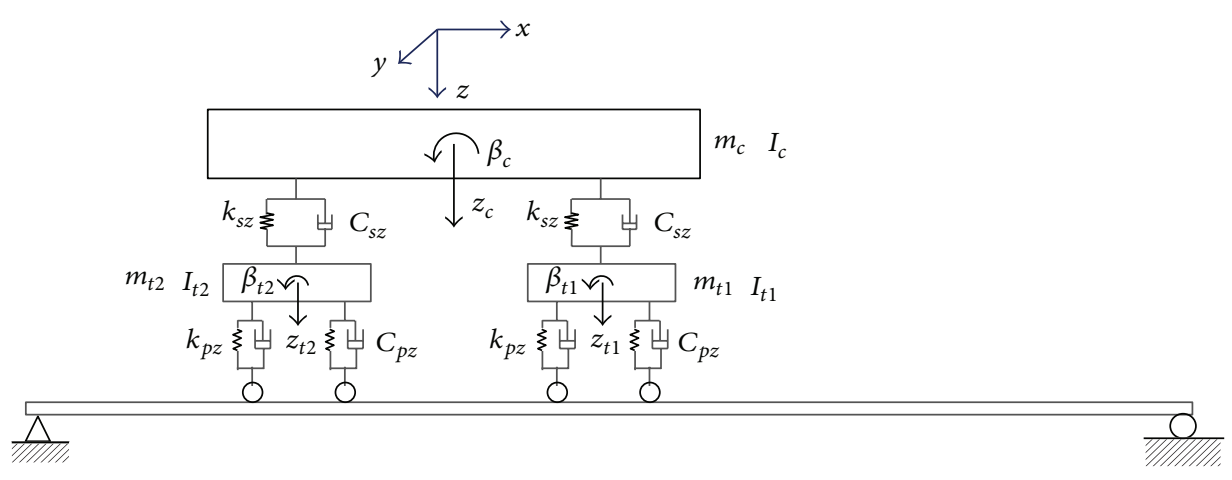

FIGURE 1: Model of train-bridge coupling system.

the excitation of the system [21]. The calculations from different samples show great differences. Majka and Hartnett [22] investigated the dynamic responses of an existing railway bridge subjected to moving trains and discussed the effect of different service trains and the random track irregularity. Monte-Carlo simulations are easily carried out but require enough number of samples to ensure the convergence of calculations, which are very time consuming and sometimes are not implementable in engineering practice especially for complex systems or problems.

In addition to performing Monte-Carlo simulations, other approaches have also been developed to analyse stochastic dynamic problems. Jin [23] employed the covariance method to calculate both displacement and accelerations of the coupling system. Pseudo excitation method (PEM) proposed by Lin et al. [24] has been widely used in linear analysis of random vibration owing to its accuracy and high efficiency. In PEM, the random excitation is transformed into pseudo excitation; then, stochastic equations of motion can be solved using numerical integration. Zhang et al. [25] investigated the influences of train speed and the three kinds of track irregularities on the three-dimensional train-bridge system based on PEM.

Many of the investigations on the stochastic characteristic of the bridge are on the simply supported beam. The integrity of the deck of multispan continuous beam is better than that of simple supported girder, so the continuous beam is widely used in Chinese high-speed railway bridge. However, most of the research on the dynamic response of the multispan continuous beam bridge is deterministic $[6,26,27]$. In this paper, the random vibration model of the time varying trainbridge coupling system is developed. The vehicle is treated as a combination of several rigid bodies which are connected by springs and dampers. The bridge is modelled using the finite element method. The vertical rail irregularity which is treated as internal excitation is constructed as pseudo excitation. Then, the random vibration equations of the bridge system and the vehicle system are integrated into a coupling system based on the equilibrium of the forces and the deformation compatibility. The stochastic characteristics of the bridge and the vehicles are obtained in the time domain by an iterative procedure at each time step. We focus on the effect of the randomness of the vertical rail irregularity on the dynamic responses of the continuous beam bridge and the running rail cars. Furthermore, the dispersal of the safety and the riding comfort of the vehicles are investigated.

The remaining parts of this paper are organised as follows. Section 2 presents the train-bridge coupling system used in this study. Section 3 summarises the pseudo excitation method for time-invariant system. Pseudo load and solution method for time-variant train-bridge system are derived in Sections 4 and 5. Section 6 investigates the safety and riding quality of the railway cars. The developed model is validated by using Monte-Carlo method in Section 7. A comprehensive analysis of the train-bridge coupling system with vertical track irregularity is conducted in Section 8. Conclusions are drawn in Section 9.

\section{Train-Bridge Coupling System}

In the train-bridge coupling system, a multibody model is used to represent a moving railway car and a spatial beam element is adopted to simulate the bridge system as shown in Figure 1 . Here, the subscripts $c, t_{1}$, and $t_{2}$ represent the car body, front bogie, and back bogie, respectively; $z$ and $\beta$ represent the vertical displacement and rotation about $y$-axis; $m_{c}, m_{t 1}$, and $m_{t 2}$ denote the mass of car body, front bogie, and back bogie, respectively; the primary suspension system is demonstrated by four linear springs with stiffness $k_{p z}$ and four dampers with damping coefficient $C_{p z}$; the secondary suspension system is represented by two linear springs with stiffness $k_{s z}$ and two dampers with damping coefficient $C_{s z}$; $I_{c}, I_{t 1}$, and $I_{t 2}$ denote the moment of inertia of the car body, front bogie, and back bogie, respectively.

In this study, the railway car is modelled by a multibody connected by the primary and secondary springs with 6 degrees of freedom as shown in Figure 1. The dynamic equations of the vehicle system can be written in the matrix form as

$$
\left[\mathbf{M}_{v}\right]\left\{\ddot{\mathbf{u}}_{v}\right\}+\left[\mathbf{C}_{v}\right]\left\{\dot{\mathbf{u}}_{v}\right\}+\left[\mathbf{K}_{v}\right]\left\{\mathbf{u}_{v}\right\}=\left\{\mathbf{F}_{\mathbf{v}}\right\}
$$

where subscript $v$ represents the vehicle. $\left[\mathbf{M}_{v}\right],\left[\mathbf{C}_{v}\right]$, and $\left[\mathbf{K}_{v}\right]$ are the mass, damping, and stiffness matrices of the vehicle 


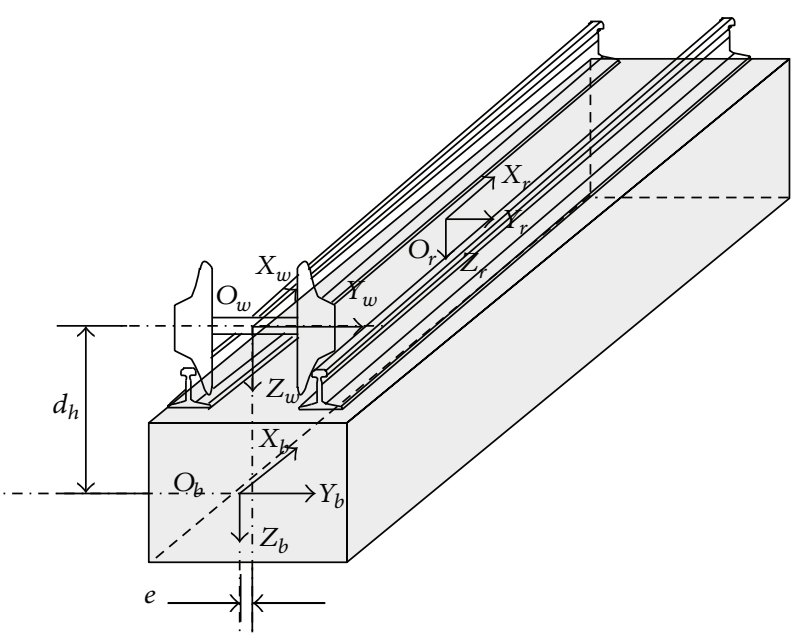

Figure 2: Compatibility condition of the displacement.

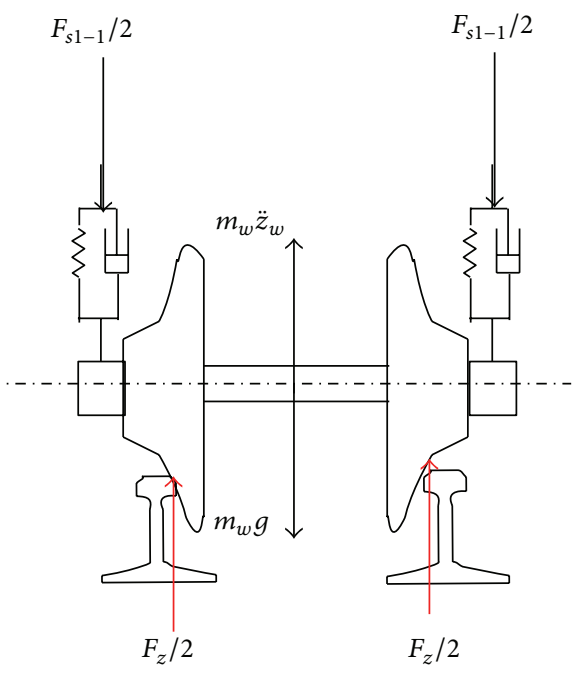

FIGURE 3: Wheel/rail forces.

[28], $\left\{\ddot{\mathbf{u}}_{v}\right\},\left\{\dot{\mathbf{u}}_{v}\right\}$, and $\left\{\mathbf{u}_{v}\right\}$ are the acceleration, velocity, and displacement of the vehicle, respectively, and

$$
\left\{\mathbf{u}_{v}\right\}=\left(\begin{array}{llllll}
z_{c} & \beta_{c} & z_{t 1} & \beta_{t 1} & z_{t 2} & \beta_{t 2}
\end{array}\right)^{T} .
$$

$\left\{\mathbf{F}_{v}\right\}$ is the interaction vector applied to the vehicle due to the vibration of the track; that is,

$$
\left\{\mathbf{F}_{v}\right\}=\left(\begin{array}{llllll}
F_{z c} & M_{y c} & F_{z t 1} & M_{z t 1} & F_{z t 2} & M_{z t 2}
\end{array}\right)^{T},
$$

where $F$ and $M$ denote force and moment, respectively; subscripts $z$ and $y$ denote vertical and horizontal direction, respectively. Since the car body and track have no direct contact, $F_{z c}$ and $M_{y c}$ equal zero.

A spatial beam element model is applied to simulate the bridge system. Equations of motion of the bridge system can then be expressed as

$$
\left[\mathbf{M}_{b}\right]\left\{\ddot{\mathbf{u}}_{b}\right\}+\left[\mathbf{C}_{b}\right]\left\{\dot{\mathbf{u}}_{b}\right\}+\left[\mathbf{K}_{b}\right]\left\{\mathbf{u}_{b}\right\}=\left\{\mathbf{F}_{b}\right\},
$$

where subscript $b$ denotes the bridge; $\left[\mathbf{M}_{b}\right],\left[\mathbf{C}_{b}\right]$, and $\left[\mathbf{K}_{b}\right]$ are the mass, damping, and stiffness matrices of the bridge $[21,28] ;\left\{\ddot{\mathbf{u}}_{b}\right\},\left\{\dot{\mathbf{u}}_{b}\right\}$, and $\left\{\mathbf{u}_{b}\right\}$ are the acceleration, velocity, and displacement of the bridge system with

$$
\left\{\mathbf{u}_{b}\right\}=\left(\begin{array}{llllll}
x_{b} & y_{b} & z_{b} & \theta_{x b} & \theta_{y b} & \theta_{z b}
\end{array}\right)^{T} .
$$

$\left\{\mathbf{F}_{b}\right\}$ is the interaction vector applied to the bridge deck due to the vibration of the moving train.

The interaction between the train and bridge can be calculated through the compatibility condition of the displacement and equilibrium equations of the wheel/rail forces (see Figures 2 and 3 ).

In Figure 2, $O_{b}-X_{b} Y_{b} Z_{b}$ is the coordinate system of the bridge model, $O_{w}-X_{w} Y_{w} Z_{w}$ is the coordinate system of the wheelset model, and $O_{r}-X_{r} Y_{r} Z_{r}$ is the coordinate system of the track model. Assuming the wheelset and the track are 
constantly connected, the displacement of the track centre $z_{r s}$ equals displacement of the wheelset $z_{w}$, and

$$
z_{r s}=z_{w}=z_{b}+e \theta_{b}+z(t)
$$

where subscript $b$ denotes the bridge; $z_{b}$ is the vertical displacement of the bridge; $e$ denotes the eccentricity of the track centre; $\theta_{b}$ denotes the rotation along the axis $x_{b}$ of the cross section; $z(t)$ is the vertical rail irregularity.

In Figure 3, subscript $w$ denotes the wheelset; $F_{s 1-1}$ and $F_{z}$ are the suspension force owing to the primary spring and the vertical wheel/rail force exerted on every wheelset, respectively. The mechanical equilibrium equation of the wheelset in vertical direction can be expressed as

$$
m_{w} \ddot{z}_{w}+F_{z}-F_{s 1-1}-m_{w} g=0
$$

(7) can be rewritten as

$$
F_{z}=F_{s 1-1}+m_{w} g-m_{w} \ddot{z}_{w}
$$

The vertical wheel/rail force vector exerted on the rail, that is, $\left(\left\{\mathbf{F}_{r z}\right\}\right)$, and the vertical wheel/rail force vector exerted on wheelset $\left(\left\{\mathbf{F}_{z}\right\}\right)$ are action and reaction, respectively. Hence, they have the same magnitudes but are in the opposite direction. Meanwhile, assuming that $\left\{\mathbf{F}_{r z}\right\}$ is fully transferred to the bridge element, the single wheel load vector of the bridge element can be written as

$$
\left\{\mathbf{F}_{b w}\right\}=\left[\begin{array}{ccc}
1 & 0 & 0 \\
0 & 1 & 0 \\
d_{h} & e & 1
\end{array}\right]\left\{\begin{array}{c}
F_{r y} \\
F_{r z} \\
M_{r x}
\end{array}\right\},
$$

where $F_{r y}$ is the lateral wheel/rail force exerted on the rail; $M_{r x}$ is the moment around $x$-axis exerted on the rail; and $d_{h}$ is the vertical distance between the centroid of the bridge section and the centre of the rail.

After converting the single wheel load vector $\left(\left\{\mathbf{F}_{b w}\right\}\right)$ to the nodal load vector, $\left\{\mathbf{F}_{b}\right\}$ in (10) can be written as

$$
\left\{\mathbf{F}_{b}\right\}=\sum_{i=1}^{n_{w}}\left\{\mathbf{F}_{b w, i}\right\},
$$

where $n_{w}$ is the total number of the wheelsets.

\section{Pseudo Excitation Method (PEM) for Time-Invariant System}

Equation (11) shows the principle of PEM [29]. Here, $H(\omega)$ denotes the frequency response function. As shown in (a), if the random force is equal to $e^{i \omega t}$, then the corresponding harmonic response can be expressed as $y=H e^{i \omega t}$. Hence,

$$
\begin{aligned}
& \text { (a) } x=e^{i \omega t} \longrightarrow H(\omega) \longrightarrow y=H e^{i \omega t} \\
& \text { (b) } \tilde{x}=\sqrt{S_{x x}(\omega)} e^{i \omega t} \longrightarrow H(\omega) \longrightarrow y=\sqrt{S_{x x}(\omega)} H_{1} e^{i \omega t}, z=\sqrt{S_{x x}(\omega)} H_{2} e^{i \omega t} .
\end{aligned}
$$

Pseudo excitation shown in (b) is constructed [24] as follows:

$$
\tilde{x}(t)=\sqrt{S_{x x}} e^{i \omega t}
$$

The corresponding pseudo response is given by

$$
\tilde{y}=\sqrt{S_{x x}} H e^{i \omega t}
$$

where (\#) denotes the pseudo expression of (\#). The autopower spectral density of the dynamic response can be taken as

$$
\tilde{y}^{*} \cdot \tilde{y}=H_{1}^{*} \sqrt{S_{x x}} e^{-i \omega t} \cdot H_{1} \sqrt{S_{x x}} e^{i \omega t}=|H|^{2} S_{x x}=S_{y y},
$$

where superscript “*” denotes the complex conjugation.
If the two pseudo variables are obtained, the cross-power spectral density can be taken as

$$
\begin{aligned}
& \tilde{y}^{*} \cdot \widetilde{z}=H_{1}^{*} \sqrt{S_{x x}} e^{-i \omega t} \cdot H_{2} \sqrt{S_{x x}} e^{i \omega t}=H_{1}^{*} S_{x x} H_{2} \\
& =S_{y z} \\
& \tilde{z}^{*} \cdot \tilde{y}=H_{2}^{*} S_{x x} H_{1}=S_{z y} \text {. }
\end{aligned}
$$

Accordingly, the PSD matrix of the dynamic responses can be expressed as

$$
\begin{aligned}
& {\left[\mathbf{S}_{y y}\right]=\{\widetilde{\mathbf{y}}\}^{*} \cdot\{\widetilde{\mathbf{y}}\}^{T},} \\
& {\left[\mathbf{S}_{y z}\right]=\{\widetilde{\mathbf{y}}\}^{*} \cdot\{\widetilde{\mathbf{z}}\}^{T},} \\
& {\left[\mathbf{S}_{z y}\right]=\{\widetilde{\mathbf{z}}\}^{*} \cdot\{\widetilde{\mathbf{y}}\}^{T} .}
\end{aligned}
$$

If the dynamic responses are linear with the excitation, the pseudo excitation method can be applied. For linear structures, the stationary random responses can be determined by means of harmonic vibration analyses, while the nonstation- 
ary random responses can be computed by means of an arbitrary direct integration scheme. Therefore, all these random response analyses become simple by using the PEM [30].

\section{PEM Method for Time-Variant Train-Bridge Coupling System}

In this paper, vertical track irregularity is considered as random progress with zero mean. The kinetic equation of the coupled system can be expressed as follows:

$$
\begin{aligned}
& {[\mathbf{M}]\{\ddot{\mathbf{y}}(t)\}+[\mathbf{C}]\{\dot{\mathbf{y}}(t)\}+[\mathbf{K}]\{\mathbf{y}(t)\}} \\
& \quad=\left\{\mathbf{F}_{1}(t)\right\}+\left\{\mathbf{F}_{2}(t)\right\},
\end{aligned}
$$

where $[\mathbf{M}],[\mathbf{C}]$, and $[\mathbf{K}]$ are the mass, damping, and stiffness matrix, respectively; $\{\ddot{\mathbf{y}}(t)\},\{\dot{\mathbf{y}}(t)\}$, and $\{\mathbf{y}(t)\}$ are the acceleration, velocity, and displacement vector, respectively; $\left\{\mathbf{F}_{1}(t)\right\}$ is the deterministic load vector mainly generated by the weight of the vehicles; and $\left\{\mathbf{F}_{2}(t)\right\}$ is the random load vector caused by the vertical track irregularity.

Equation (17) can be solved by using Duhamel integration with respect to $t$ over the period when the train moves on the bridge; it obtains

$$
\{\mathbf{y}(t)\}=\int_{0}^{t}[\mathbf{H}(t-\tau)]\left(\left\{\mathbf{F}_{1}(\tau)\right\}+\left\{\mathbf{F}_{2}(\tau)\right\}\right) d \tau .
$$

The mean value of the responses can be written as

$$
\begin{aligned}
\overline{\{\mathbf{y}(t)\}} & =E[\{\mathbf{y}(t)\}] \\
& =\int_{0}^{t}[\mathbf{H}(t-\tau)] E\left(\left\{\mathbf{F}_{1}(\tau)\right\}+\left\{\mathbf{F}_{2}(\tau)\right\}\right) d \tau .
\end{aligned}
$$

As $E\left[\left\{\mathbf{F}_{2}(t)\right\}\right]=0$, (19) can be simplified as

$$
\overline{\{\mathbf{y}(t)\}}=\int_{0}^{t}[\mathbf{H}(t-\tau)] E\left(\left\{\mathbf{F}_{1}(\tau)\right\}\right) d \tau .
$$

The autocovariance of the responses can be calculated by

$$
\begin{aligned}
& {\left[\mathbf{R}_{y y}\left(t_{k}, t_{l}\right)\right]} \\
& \quad=E\left[\left(\left\{\mathbf{y}\left(t_{k}\right)\right\}-\overline{\left\{\mathbf{y}\left(t_{k}\right)\right\}}\right)\left(\left\{\mathbf{y}\left(t_{l}\right)\right\}-\overline{\left\{\mathbf{y}\left(t_{l}\right)\right\}}\right)^{T}\right] .
\end{aligned}
$$

Substituting (18) and (19) into (21) yields

$$
\begin{aligned}
& {\left[\mathbf{R}_{y y}\left(t_{k}, t_{l}\right)\right]=\int_{0}^{t_{k}} \int_{0}^{t_{l}}\left[\mathbf{H}_{k}\left(t_{k}-\tau_{k}\right)\right]} \\
& \quad \cdot E\left[\left\{\mathbf{F}_{2}\left(\tau_{k}\right)\right\}\left\{\mathbf{F}_{2}\left(\tau_{l}\right)\right\}^{T}\right]\left[\mathbf{H}_{l}\left(t_{l}-\tau_{l}\right)\right]^{T} d \tau_{k} d \tau_{l} .
\end{aligned}
$$

$\left\{\mathbf{F}_{2}(t)\right\}$ can be written as

$$
\left\{\mathbf{F}_{2}(t)\right\}=[\boldsymbol{\alpha}(t)]\{\mathbf{z}(t)\},
$$

where $[\boldsymbol{\alpha}(t)]$ is the transition matrix; $\{\mathbf{z}(t)\}$ is the vertical profile irregularity vector; that is, $\{\mathbf{z}(t)\}=\left(z_{1}(t) z_{2}(t) \cdots\right.$ $\left.z_{n-1}(t) z_{n}(t)\right)^{T}$ ( $n$ is the sum of the wheelsets and $z_{i}(t)=$ $\left.z\left(t-t_{i}\right), i=1, \ldots, n\right)$.
Substituting (23) into (22) yields

$$
\begin{aligned}
{\left[\mathbf{R}_{y y}\left(t_{k}, t_{l}\right)\right]=\int_{0}^{t_{k}} \int_{0}^{t_{l}}\left[\mathbf{H}_{k}\left(t_{k}-\tau_{k}\right)\right]\left[\boldsymbol{\alpha}\left(\tau_{k}\right)\right] } \\
\cdot E\left[\left\{\mathbf{z}\left(\tau_{k}\right)\right\}\left\{\mathbf{z}\left(\tau_{l}\right)\right\}^{T}\right]\left[\boldsymbol{\alpha}\left(\tau_{l}\right)\right]^{T} \\
\cdot\left[\mathbf{H}_{k}\left(t_{k}-\tau_{k}\right)\right]^{T} d \tau_{k} d \tau_{l} .
\end{aligned}
$$

Here, the Wiener-Khintchine relation is adopted:

$$
R_{x x}(\tau)=\int_{-\infty}^{\infty} S_{x x}(f) e^{i \omega \tau} d \tau .
$$

Then, the autocovariance of the responses becomes

$$
\begin{aligned}
& {\left[\mathbf{R}_{y y}\left(t_{k}, t_{l}\right)\right]=\int_{0}^{t_{k}} \int_{0}^{t_{l}}\left[\mathbf{H}_{k}\left(t_{k}-\tau_{k}\right)\right]\left[\boldsymbol{\alpha}\left(\tau_{k}\right)\right]} \\
& \cdot \int_{-\infty}^{\infty}\{\mathbf{Q}(t)\}^{*}\{\mathbf{Q}(t)\}^{T} S(\omega) e^{i \omega\left(\tau_{l}-\tau_{k}\right)} d \omega\left[\boldsymbol{\alpha}\left(\tau_{l}\right)\right]^{T} \\
& \cdot\left[\mathbf{H}_{l}\left(t_{l}-\tau_{l}\right)\right]^{T} d \tau_{l} d \tau_{k} \\
& =\int_{-\infty}^{\infty}\left(\int_{0}^{\tau_{k}}\left[\mathbf{H}_{k}\left(t_{k}-\tau_{k}\right)\right]\left[\boldsymbol{\alpha}\left(\tau_{k}\right)\right]\{\mathbf{Q}(t)\}^{*}\right. \\
& \left.\cdot e^{-i \omega \tau_{k}} d \tau_{k}\right) \\
& \cdot\left(\int_{0}^{\tau_{l}}\{\mathbf{Q}(t)\}^{T}\left[\boldsymbol{\alpha}\left(\tau_{l}\right)\right]^{T}\left[\mathbf{H}_{l}\left(t_{l}-\tau_{l}\right)\right]^{T} e^{i \omega \tau_{l}} d \tau_{l}\right) \\
& \cdot S(\omega) d \omega,
\end{aligned}
$$

where superscript $*$ denotes the complex conjugation; $S(\omega)$ is the PSD of the vertical rail irregularity; and

$$
\{\mathbf{Q}(t)\}=\left(\begin{array}{llll}
e^{-i \omega t_{1}} & e^{-i \omega t_{2}} & \cdots & e^{-i \omega t_{n}}
\end{array}\right)^{T} .
$$

Assuming that

$$
\{\mathbf{I}(\omega, t)\}=\int_{0}^{t}[\mathbf{H}(t-\tau)][\boldsymbol{\alpha}(\tau)]\{\mathbf{Q}(t)\} e^{i \omega \tau} d \tau .
$$

(26) can be rewritten as

$$
\left[\mathbf{R}_{y y}\left(t_{k}, t_{l}\right)\right]=\int_{-\infty}^{\infty}\left\{\mathbf{I}_{k}\left(\omega, t_{k}\right)\right\}^{*}\left\{\mathbf{I}_{l}\left(\omega, t_{l}\right)\right\} S(\omega) d \omega .
$$

Let $t_{k}=t_{l}=t$; we have

$$
\left[\mathbf{R}_{y y}(t, t)\right]=\int_{-\infty}^{\infty}\left\{\mathbf{I}_{k}(\omega, t)\right\}^{*}\left\{\mathbf{I}_{l}(\omega, t)\right\} S(\omega) d \omega .
$$

From (25) and (30), it can be obtained that

$$
\begin{aligned}
{\left[\mathbf{R}_{y y}(t, t)\right] } & =\int_{-\infty}^{\infty}\left[\mathbf{s}_{y y}(\omega)\right] e^{i \omega(t-t)} d \omega \\
& =\int_{-\infty}^{\infty}\left[\mathbf{s}_{y y}(\omega)\right] d \omega,
\end{aligned}
$$

where $\left[\mathbf{S}_{y y}(\omega)\right]$ is the autopower spectral density of the dynamic responses. 
Furthermore,

$$
\left[\mathbf{S}_{y y}(\omega)\right]=\left\{\mathbf{I}_{k}(\omega, t)\right\}^{*}\left\{\mathbf{I}_{l}(\omega, t)\right\}^{T} S(\omega) .
$$

From (28), $\{\mathbf{I}(\omega, t)\}$ can be regarded as the response vector caused by the excitation vector $[\boldsymbol{\alpha}(t)]\{\mathbf{Q}(t)\} e^{i \omega t}$; thus, the pseudo excitation of the coupling system can be instituted $[28,29]$ :

$$
\{\widetilde{\mathbf{z}}(t)\}=[\boldsymbol{\alpha}(t)]\{\mathbf{Q}(t)\} e^{i \omega t} \sqrt{S(\omega)},
$$

where superscript $\sim$ denotes "pseudo."

Therefore, the responses vector induced by the pseudo load vector as indicated in (33) can be obtained by

$$
\begin{aligned}
\{\widetilde{\mathbf{y}}(\omega, t)\} & =\int_{0}^{t}[\mathbf{H}(\omega, t)][\boldsymbol{\alpha}(\tau)]\{\mathbf{Q}(\tau)\} e^{i \omega t} \sqrt{S(\omega)} d \tau \\
& =\{\mathbf{I}(\omega, t)\} \sqrt{S(\omega)} .
\end{aligned}
$$

So the auto-PSD matrix of the response vector can be expressed as [28]

$$
\begin{aligned}
& \left\{\widetilde{\mathbf{y}}_{k}(\omega, t)\right\}^{*}\left\{\widetilde{\mathbf{y}}_{l}(\omega, t)\right\}^{T} \\
& \quad=\left\{\widetilde{\mathbf{I}}_{k}(\omega, t)\right\}^{*}\left\{\widetilde{\mathbf{I}}_{l}(\omega, t)\right\}^{T} S(\omega) .
\end{aligned}
$$

From the principle of the pseudo excitation method and (3), the auto-PSD matrix of the response vector can also be written as

$$
\left\{\widetilde{\mathbf{y}}_{k}(\omega, t)\right\}^{*}\left\{\widetilde{\mathbf{y}}_{l}(\omega, t)\right\}^{T}=\left[\mathbf{S}_{y y}(\omega, t)\right] .
$$

Therefore,

$$
\left[\mathbf{S}_{y y}(\omega, t)\right]=\left\{\widetilde{\mathbf{I}}_{k}(\omega, t)\right\}^{*}\left\{\widetilde{\mathbf{I}}_{l}(\omega, t)\right\}^{T} S(\omega) .
$$

The expression of (32) is the same as (37). Consequently, the assumption of the pseudo load vector expressed in (33) is logical.

\section{Solutions to the Random Characteristics of Train-Bridge Coupling System}

The problems presented in the above section can be solved by applying the numerical integration and programming to the following analysis process:

(1) Average value can be obtained by using (20).

(2) PSD and SD of the dynamic responses of the trainbridge system are obtained as shown in the flowchart (Figure 4).

\section{Safety and Riding Quality of the Railway Cars}

When normal contact conditions between the wheels and the rail are satisfied, the safety of the running vehicles can be guaranteed. However, under the worst load combination, the derailment or overturn accident may happen. Several parameters can be used to evaluate the safety of the trains, such as derailment coefficient, wheel unloading rate, and lateral swing force. In this paper, we choose the wheel unloading rate as the safety index of the railway cars. Riding quality can show the influence of the vibration of the train on the comfort of the passengers. In ISO2631, Janeway and Jacking comfort curves and Sperling index are usually employed to evaluate the riding quality of the running railway cars. In this study, Sperling index is used to assess the passengers' riding comfort.

6.1. Wheel Unloading Rate. When a train is moving with high speed, the dynamic wheel weight will decrease during the upward movement. Meanwhile, the wheelset may derail owing to the lateral relative displacement between the bridge deck and the wheelset in spite of small lateral wheel-rail interaction force [31]. Wheel unloading rate can be defined as the dynamic wheel load reduction amount divided by the average static wheel load, that is, $\Delta P / P[21]$.

6.2. Sperling Index. Sperling index of the comfort can be expressed as [21]

$$
W=0.896 \sqrt[10]{\frac{a^{3}}{f} F(f)},
$$

where $a$ is acceleration $\left(\mathrm{cm} / \mathrm{s}^{2}\right) ; f$ is vibration frequency $(\mathrm{Hz})$; $F(f)$ is the correction coefficient of frequency; that is,

Vertical vibration: $F(f)$

$$
= \begin{cases}0.325 f^{2}, & (f=0.5 \sim 5.9 \mathrm{~Hz}), \\ \frac{400}{f}, & (f=5.9 \sim 20 \mathrm{~Hz}), \\ 1, & (f>20 \mathrm{~Hz}) .\end{cases}
$$

\section{Verification of the Presented Computational Model}

In this section, a single span simple supported bridge is adopted to confirm the rationality of the method presented in Section 4, and only one ICE high-speed motor train [31] passes through the bridge with a speed of $220 \mathrm{~km}$ per hour. The span is $32 \mathrm{~m}$. The cross-section properties of the bridge are taken as follows: elasticity modulus is $3.45 \times 10^{10} \mathrm{~N} / \mathrm{m}^{2}$; Poisson's ratio is 0.2 ; ratio of damping is 0.02 ; area is $7.5 \mathrm{~m}^{2}$; inertia moment in $x, y$, and $z$ direction is $35.4 \mathrm{~m}^{4}, 9 \mathrm{~m}^{4}$, and $70.158 \mathrm{~m}^{4}$, respectively.

The German low-interference track irregularity spectrum is applied; that is,

$$
S(\Omega)=\frac{A_{v} \Omega_{c}^{2}}{\left(\Omega^{2}+\Omega_{r}^{2}\right)\left(\Omega^{2}+\Omega_{c}^{2}\right)},
$$

where $\Omega$ is the spatial frequency; $A_{v}$ is roughness constant of track; that is, $A_{v}=4.032 \times 10^{-7} ; \Omega_{c}$ and $\Omega_{r}$ are cut-off frequency; that is, $\Omega_{c}=0.8246$ and $\Omega_{r}=0.0206$.

Wavelength coverage of the rail irregularity is from $1 \mathrm{~m}$ to $80 \mathrm{~m}$. Eccentricity of the line equals $2.5 \mathrm{~m}$; Rayleigh damping is adopted in this study. The railway cars travel about $100 \mathrm{~m}$ on the same line as on the bridge before they pass through the 


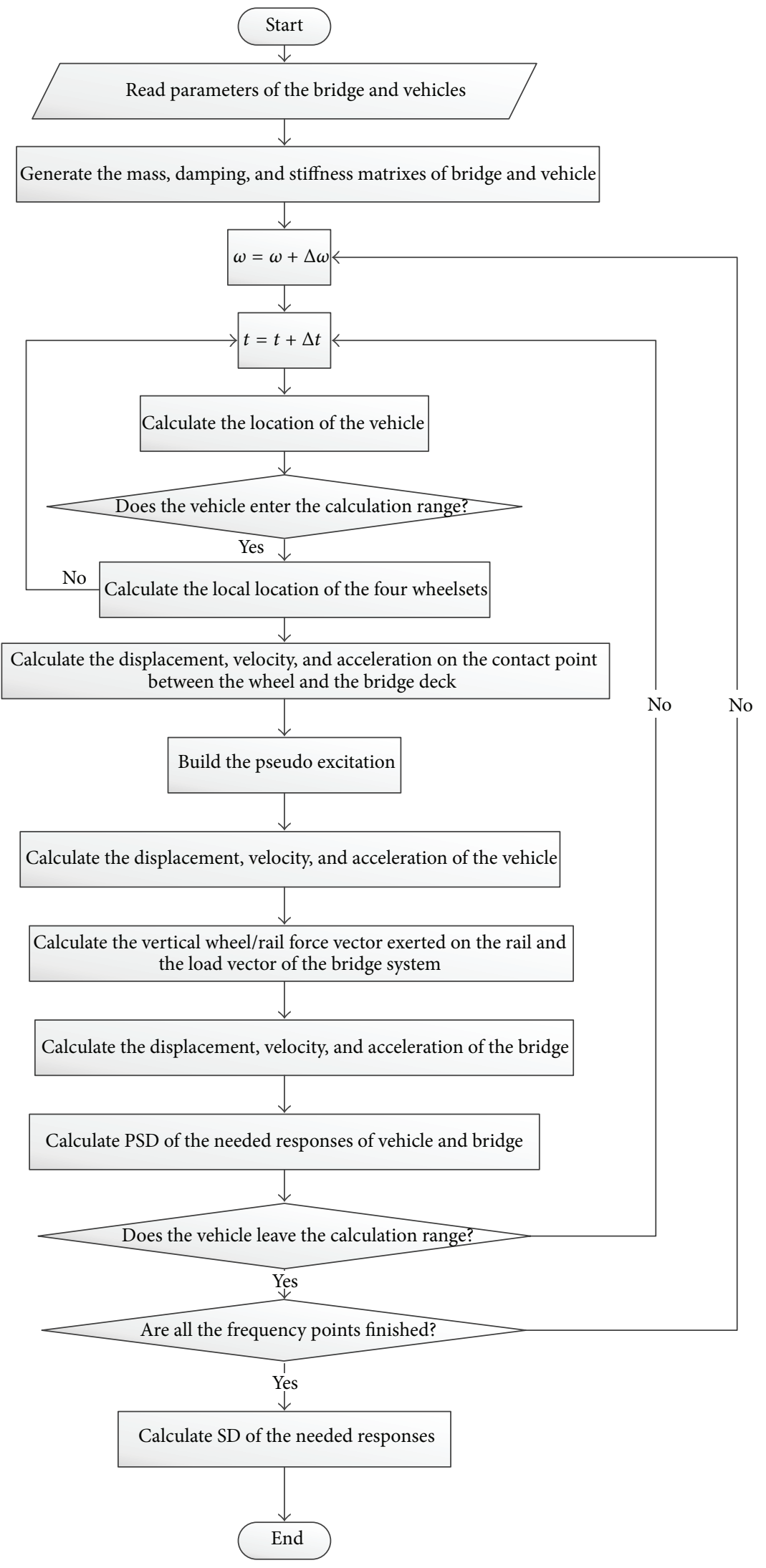

FIGURE 4: Flowchart of the dynamic responses of the train-bridge system. 


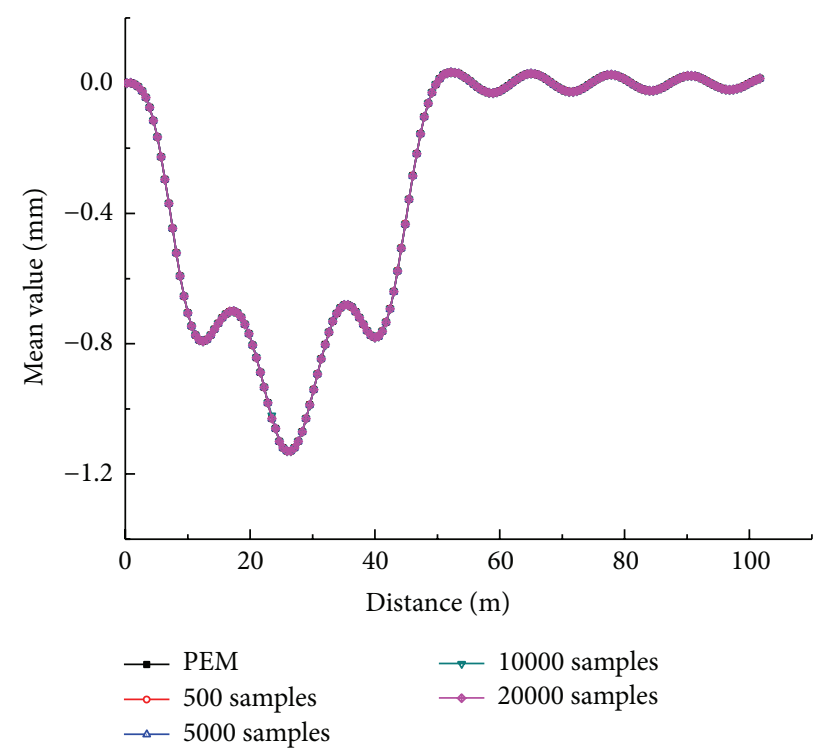

(a)

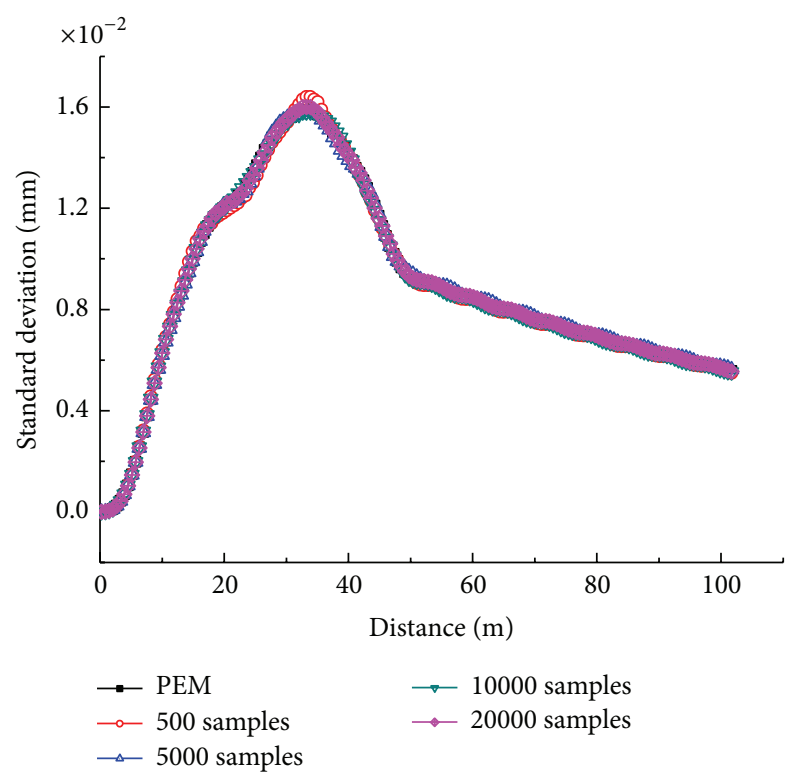

(c)

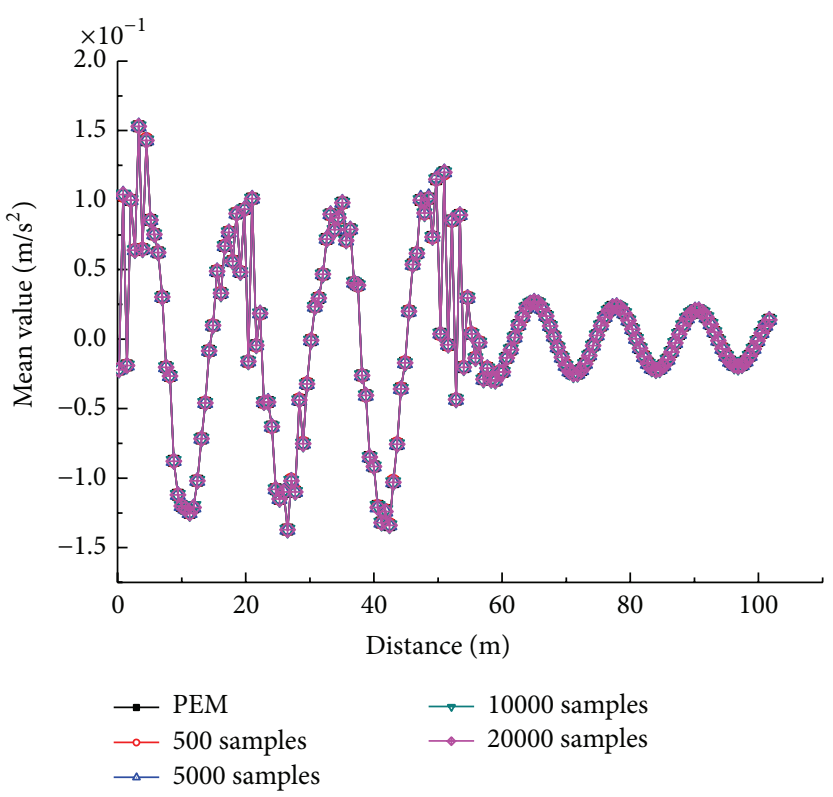

(b)

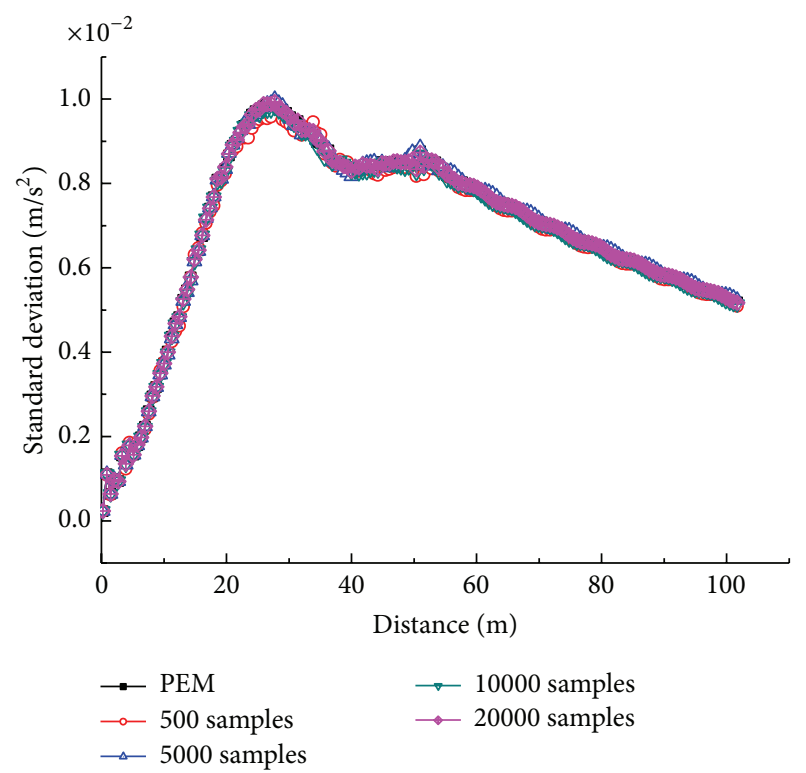

(d)

Figure 5: Statistical characteristics of the bridge response in the midpoint. (a) Mean value of the vertical displacement. (b) Mean value of the acceleration. (c) SD of the vertical displacement. (d) SD of the acceleration.

bridge and then travel about $100 \mathrm{~m}$ again after getting off the bridge. The time step of the integration procedures is $0.0005 \mathrm{~s}$.

The trigonometric series method is adopted [21] in the modelling of the rail irregularity; that is,

$$
z(x)=\sqrt{2} \sum_{i=1}^{n} \sqrt{S(\Omega) \Delta \Omega} \cos \left(\Omega_{i} x+\phi_{i}\right),
$$

where $z(x)$ is the sequence of the vertical track irregularity; $\Delta \Omega=\left(\Omega_{n}-\Omega_{1}\right) / n$, where $\Omega_{n}$ and $\Omega_{1}$ are, respectively, the upper and the lower limits of the spatial frequency:

$$
\Omega_{i}=\Omega_{1}+(i-0.5) \Delta \Omega \quad(i=1, \ldots, n) .
$$

$\phi_{i}$ is the $i$ th phase and is in accordance with the principle of uniform distribution.

To verify the results obtained by the presented method, 500, 5000, 10000, and 20000 Monte-Carlo simulations are implemented. Figures 5 and 6 show that the results calculated by the presented method, denoted by SRCTB, agree well with those obtained by using Monte-Carlo simulation method; however, the latter requires more time in the tentative calculation efforts. When the number of samples reaches 500 , the statistical characteristics of the bridge using Monte-Carlo method are satisfactory as shown in Figure 5. When sample number increases to 10000, the mean values of the car body and the first bogie obtained by using Monte-Carlo method 


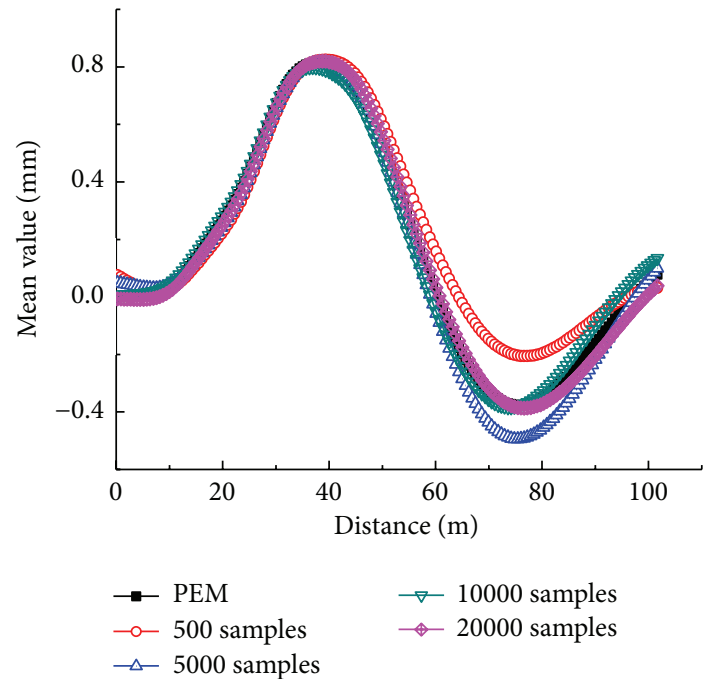

(a)

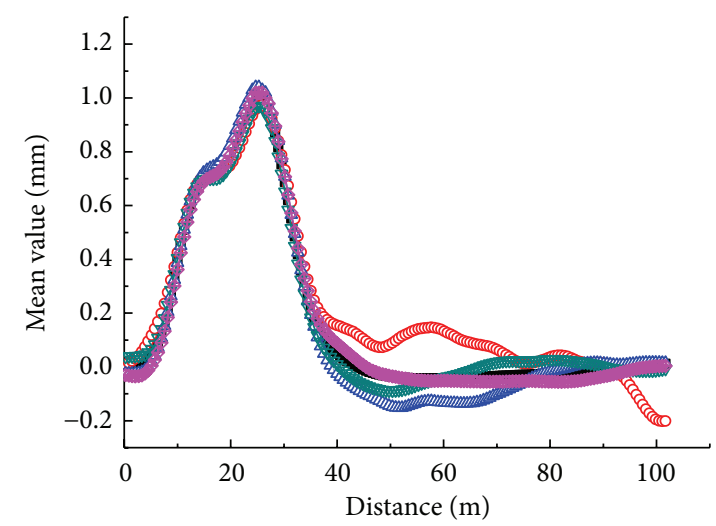

(c)

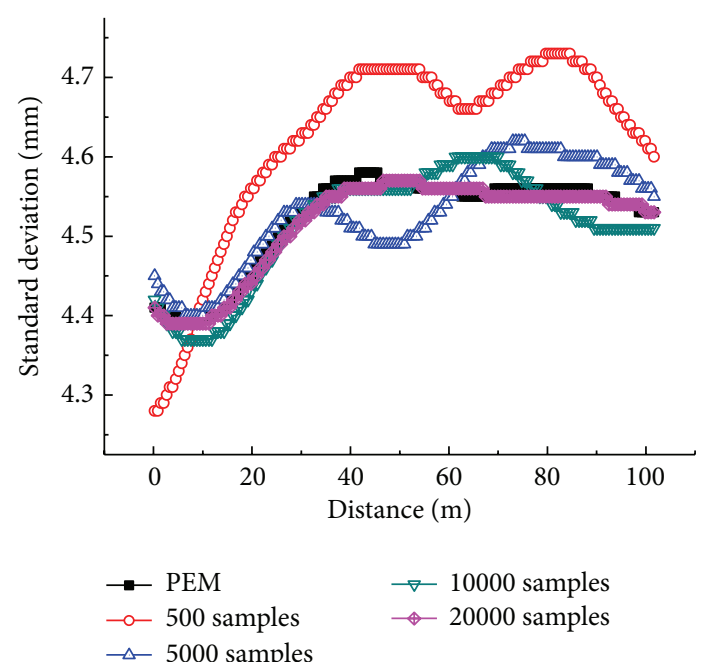

(e)

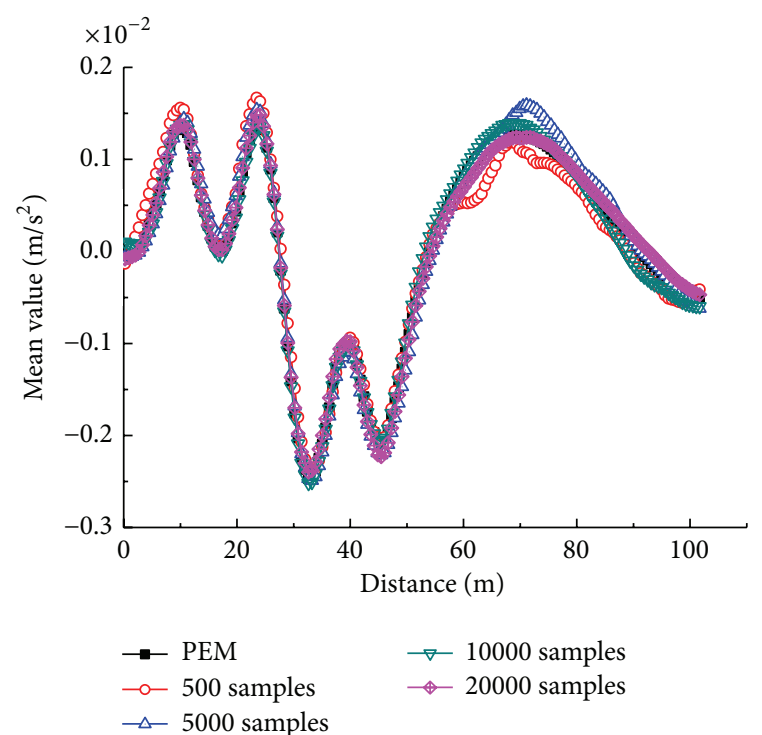

(b)

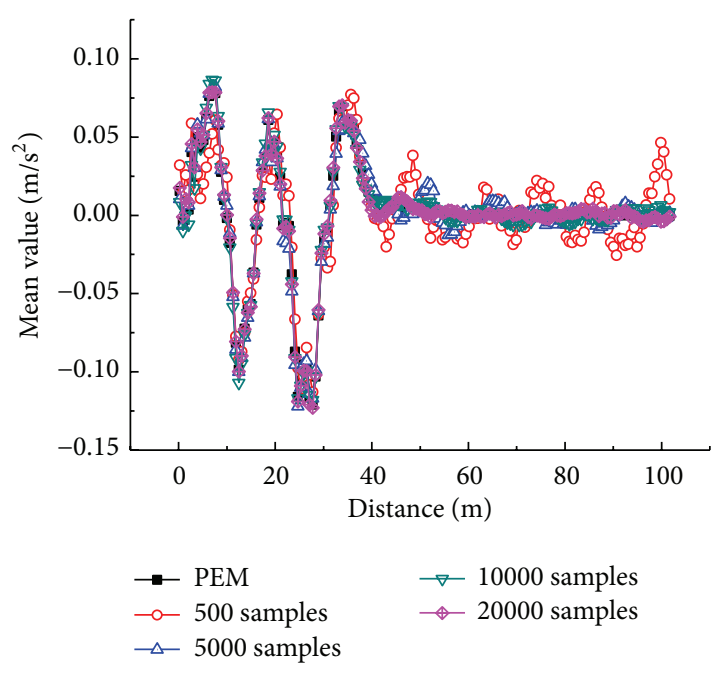

(d)

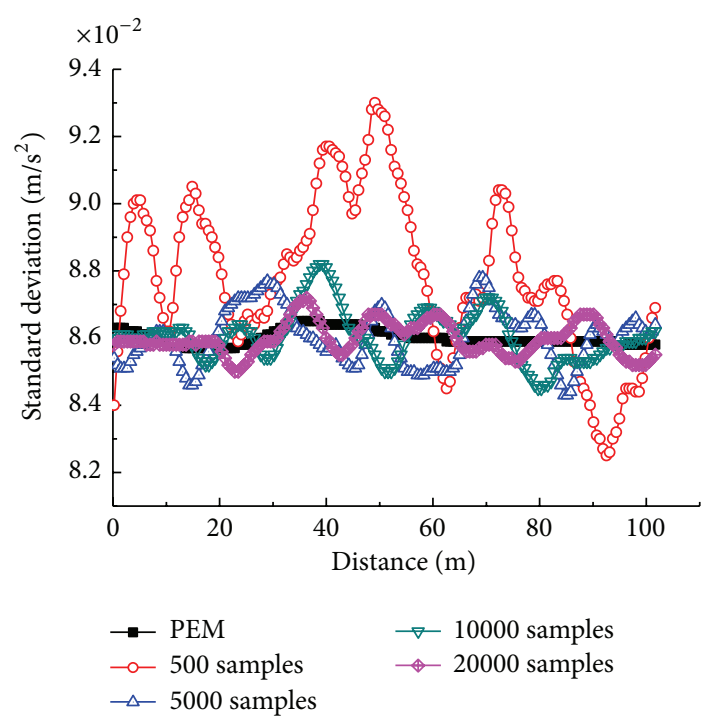

(f)

FIgURE 6: Continued. 


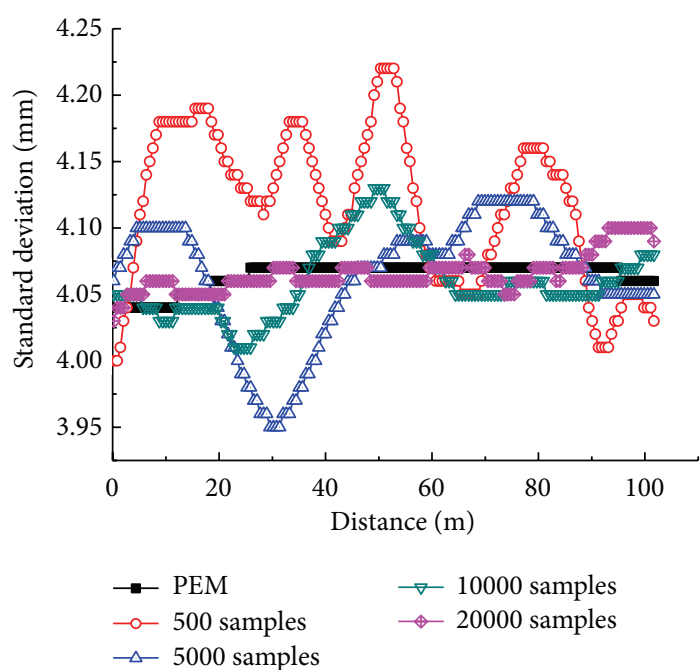

(g)

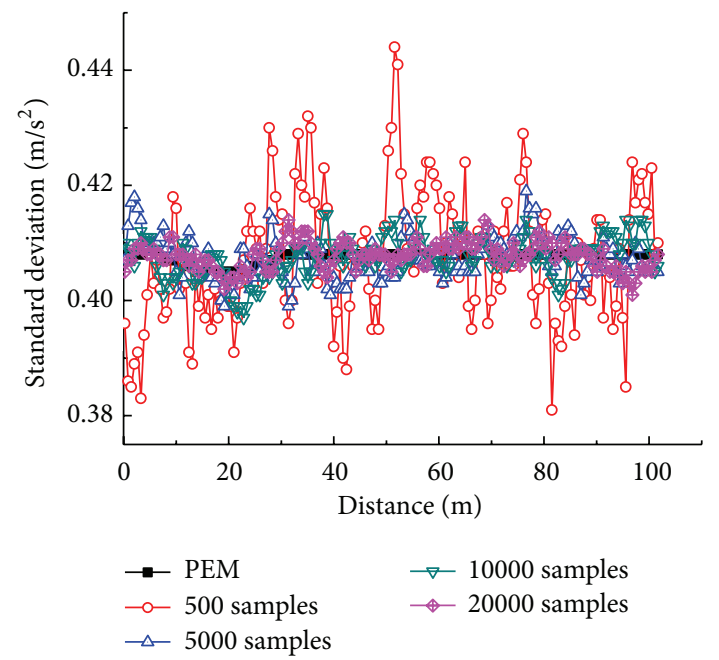

(h)

Figure 6: Statistical characteristics of the railway car. (a) Mean value of the vertical displacement of the car body. (b) Mean value of vertical acceleration of the car body. (c) Mean value of the vertical displacement of the front bogie. (d) Mean value of the vertical acceleration of the front bogie. (e) SD of the vertical displacement of the car body. (f) SD of the vertical acceleration of the car body. (g) SD of the vertical displacement of the front bogie. (h) SD of the vertical acceleration of the front bogie.

TABLE 1: Comparison of robustness and computational efficiency.

\begin{tabular}{|c|c|c|c|c|}
\hline \multirow{2}{*}{ Method } & \multirow{2}{*}{ Computational time (h) } & \multicolumn{2}{|c|}{ Robustness } & \multirow{2}{*}{ Efficiency } \\
\hline & & Bridge responses & Vehicle response & \\
\hline $\begin{array}{l}\text { Monte-Carlo } \\
\text { (500 samples) }\end{array}$ & 0.9 & Fair & Poor & Fair \\
\hline $\begin{array}{l}\text { Monte-Carlo } \\
\text { (5000 samples) }\end{array}$ & 9.8 & Fair & Poor & Poor \\
\hline $\begin{array}{l}\text { Monte-Carlo } \\
\text { (10000 samples) }\end{array}$ & 19.4 & Excellent & Fair & Poor \\
\hline $\begin{array}{l}\text { Monte-Carlo } \\
\text { (20000 samples) }\end{array}$ & 27.8 & Excellent & Excellent & Poor \\
\hline SRCTB & 0.5 & Excellent & Excellent & Excellent \\
\hline
\end{tabular}

agree very well with the calculations by applying (20). As to the standard deviation (SD) of the dynamic responses about the vehicle, 20000 samples should be required as shown in Figure 6. In Figures 5 and 6, the $x$-axis title "Distance (m)" means the distance between the first wheelset and the starting point of the bridge.

The comparison of the robustness of the dynamic responses and the computation efficiency between Monte-Carlo method and the presented method (denoted by SRCTB) is listed in Table 1. We find that SRCTB method has excellent robustness and computational efficiency.

\section{Numerical Examples}

In this section, a three-span nonuniform prestressed continuous beam bridge along the Chinese high-speed railway line is chosen to demonstrate the random properties of the trainbridge coupling system. Vehicles adopted are ICE high-speed train [30]. The bridge model is shown in Figure 7.

The cross section of the beam is a single cell box girder as shown in Figure 8. The elastic modulus is $3.55 \times 10^{10} \mathrm{~N} / \mathrm{m}^{2}$ and Poisson's ratio is 0.2 .
The wavelength coverage of the vertical rail irregularity is from $1 \mathrm{~m}$ to $80 \mathrm{~m}$; the vehicle velocity is $275 \mathrm{~km} / \mathrm{h}$; eccentricity of the rail line equals $2.5 \mathrm{~m}$; Rayleigh damping is adopted; the trains travel about $100 \mathrm{~m}$ on the same line as on the bridge before they pass through the bridge, and they travel about $100 \mathrm{~m}$ again after getting off the bridge.

8.1. Stochastic Characteristic Analysis of the Continuous Beam Bridge. As shown in Figure 9(a), vehicles loaded in the first span induce downward displacement in the first span and upward displacement in the third span.

From Figures 9(b), 10(b), and 11(a), it can be observed that the peak values of the standard value of the displacement in the midpoint of the middle span are larger than those in the midpoint of the two side spans. However, as to the peak values of the standard value of the acceleration, the opposite calculations are obtained.

As shown in Figures 9, 10, and 11, the absolute values of the mean about the bridge vertical dynamic responses are much larger than the SD of them. From (20), we believe that the vertical responses of the midpoint in the three spans are mainly affected by the certain load, that is, the wheel load. 


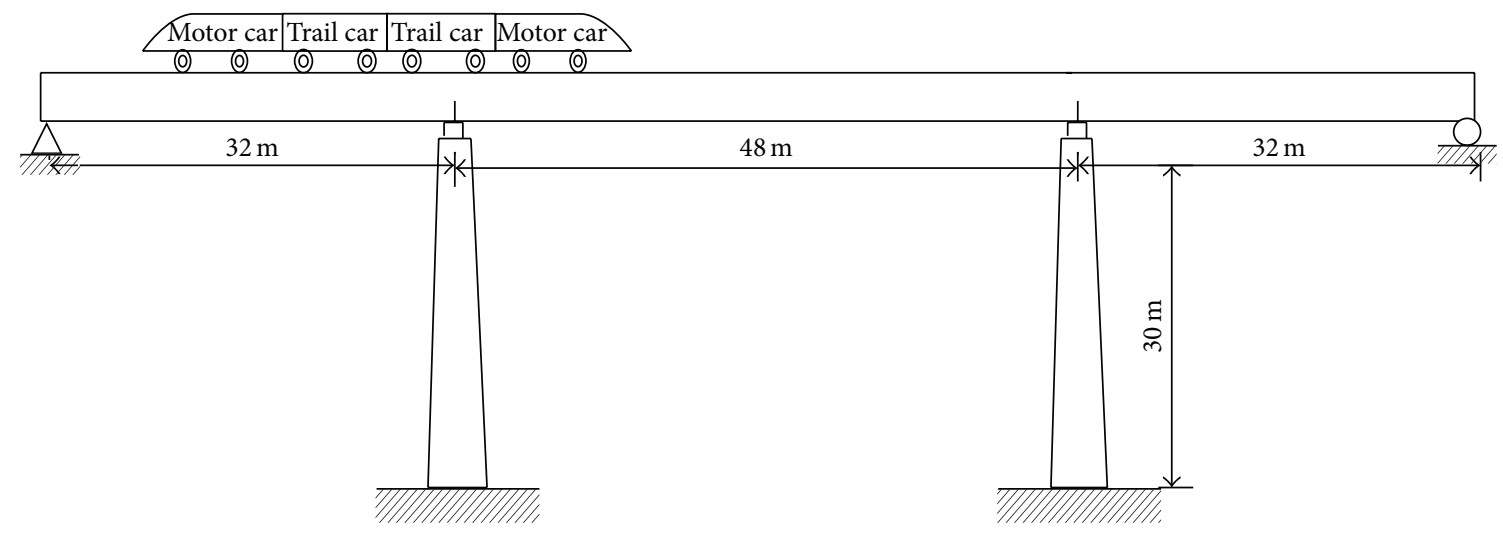

FIgURE 7: Three-span continuous beam bridge.

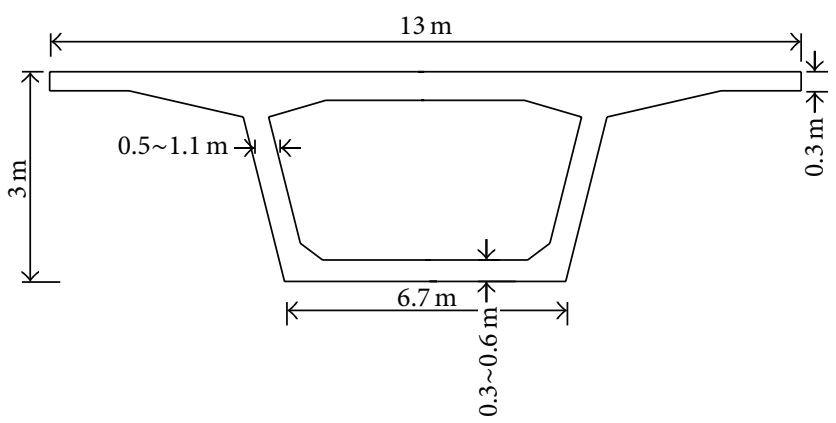

Figure 8: Cross section of the beam.
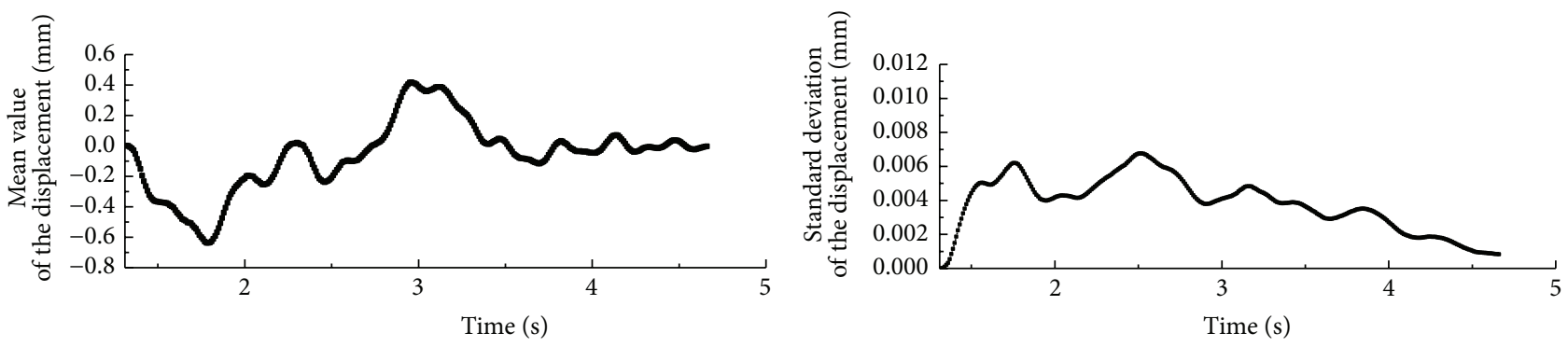

-.- In the midpoint of the first span

-.- In the midpoint of the first span

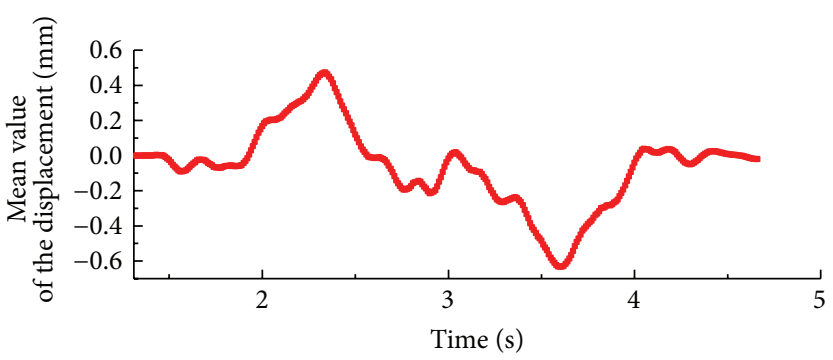

-- - In the midpoint of the third span

(a)

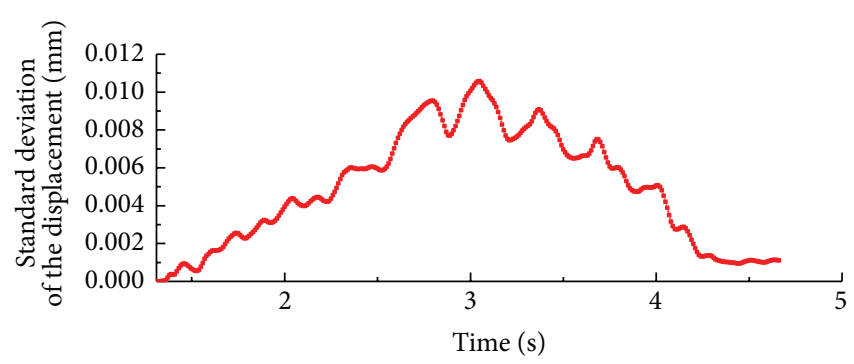

- - - In the midpoint of the third span

(b)

FIGURE 9: Displacement of the midpoint in the side span. (a) Mean value. (b) SD. 


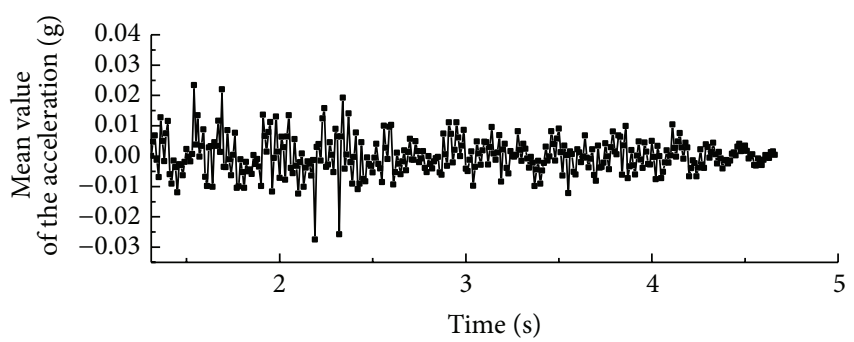

--- In the midpoint of the first span

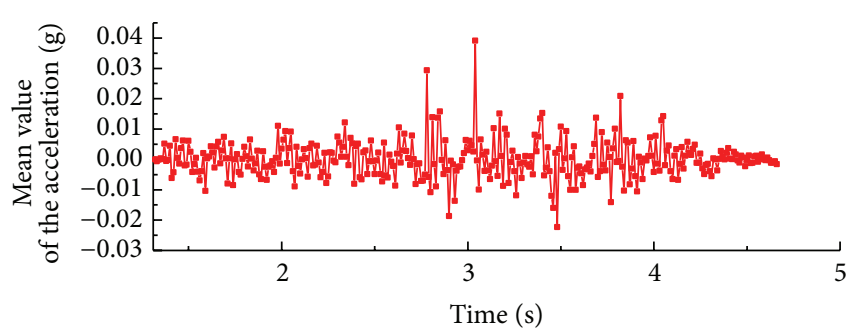

-- In the midpoint of the third span

(a)

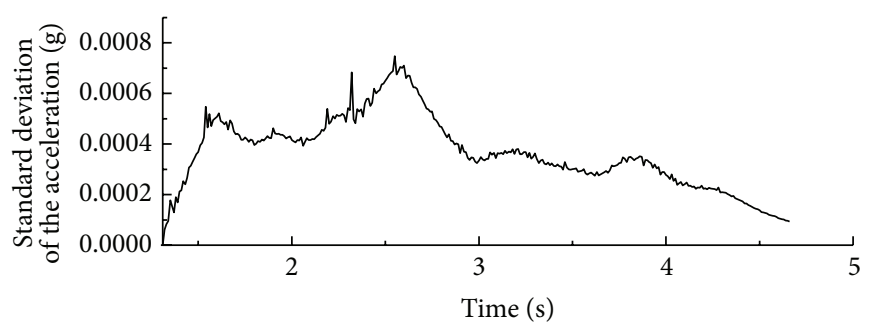

— In the midpoint of the first span

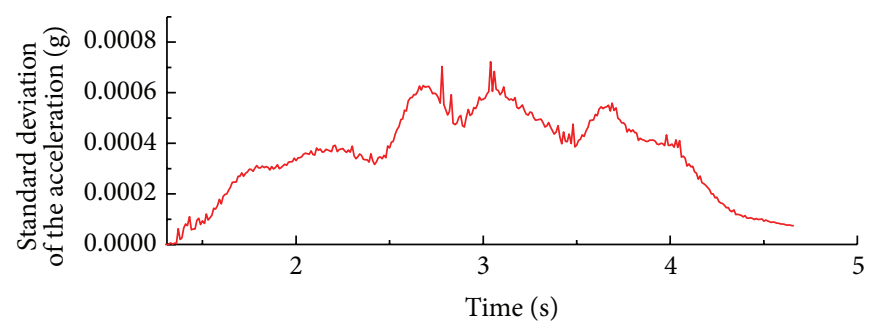

_ In the midpoint of the third span

(b)

FIgure 10: Acceleration of the midpoint in the side span. (a) Mean value. (b) SD.

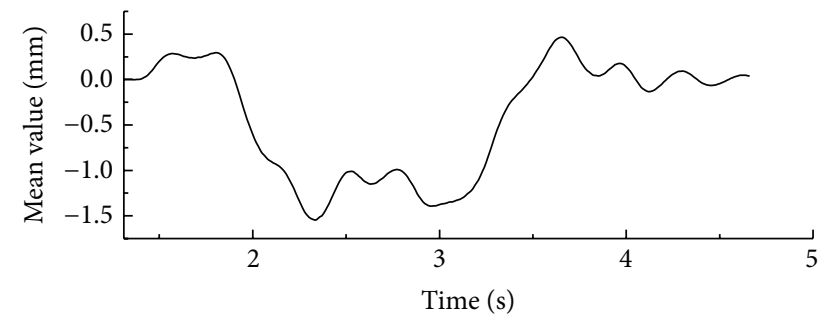

_ Displacement in the midpoint of the middle span

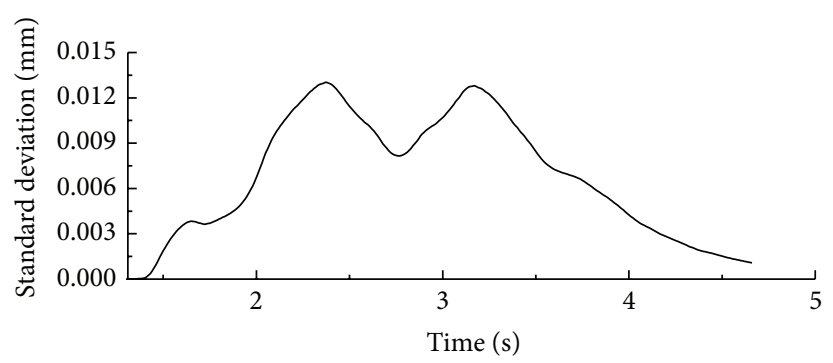

— Displacement in the midpoint of the middle span

(a)

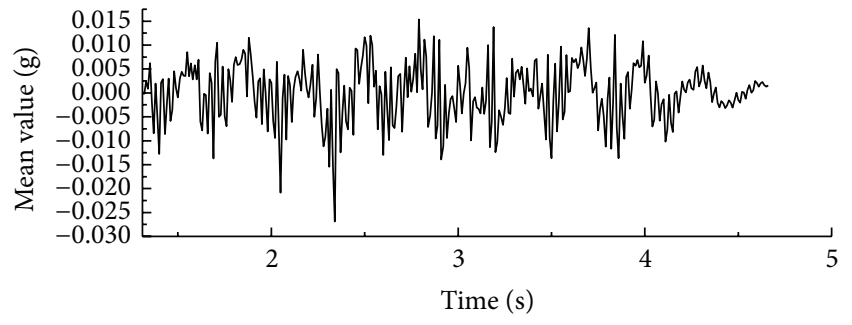

_ Acceleration in the midpoint of the middle span

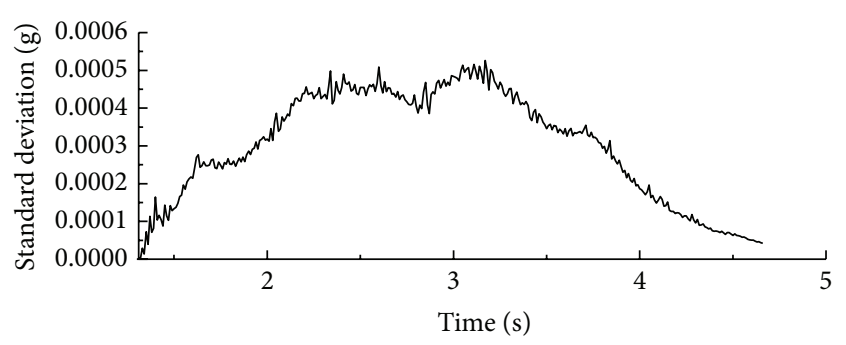

- Acceleration in the midpoint of the middle span

(b)

FIGURE 11: Dynamic responses of the midpoint in the middle span. (a) Mean value and SD of the displacement. (b) (a) Mean value and SD of the acceleration.

As shown in Figure 12, the majority of the PSDs about the displacement in the midpoint of the first span and the same place in the third span cover the same frequency range. As to the corresponding place in the middle span, its PSD is larger than that of the side spans.

From Figure 13, it can be seen that the acceleration PSDs of the midpoint in the three spans do not have similar frequency range.
The PSDs have different varying rules with each other as shown in Figures 12 and 13. The nonstationary features do exist in the dynamic responses of bridge.

8.2. Stochastic Characteristic Analysis of Vehicles. From Figures 14-17, it can be found that the mean values of dynamic responses are smaller than the standard deviations of them of railway cars. In Figure 14, the mean and the SD of 


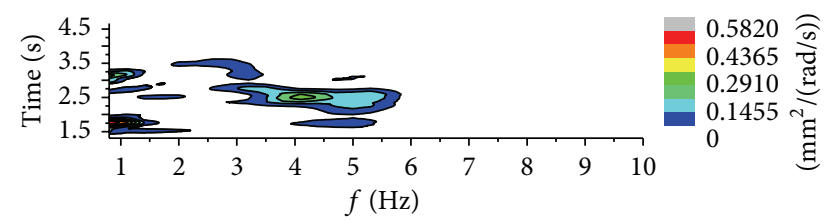

(a)

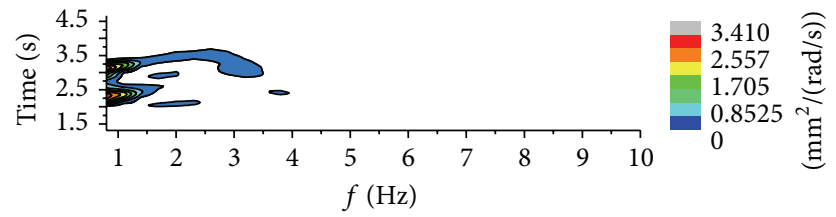

(b)

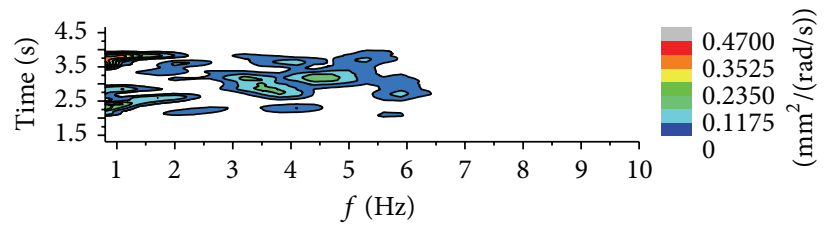

(c)

FIGURE 12: PSD of the bridge displacement of (a) midpoint of the first span, (b) midpoint of the middle span, and (c) midpoint of the third span.

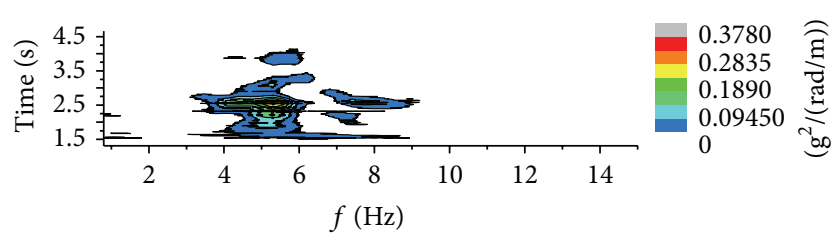

(a)

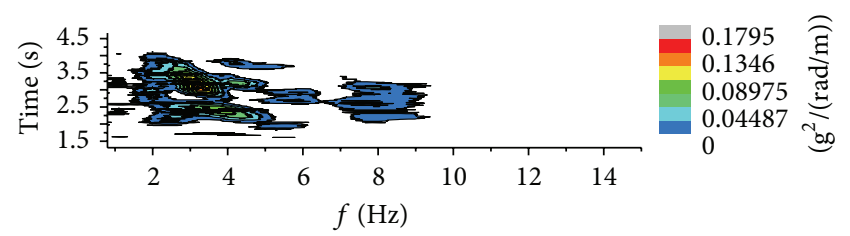

(b)

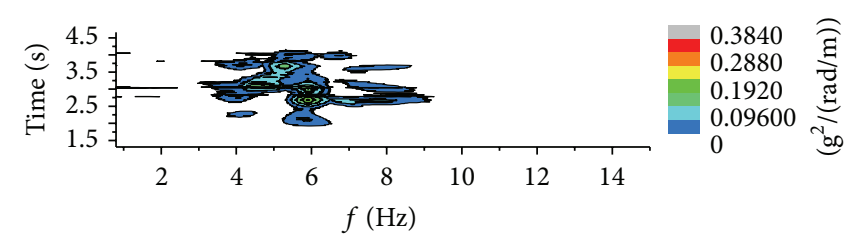

(c)

FIGURE 13: PSD of the bridge acceleration in the midpoint of (a) first span, (b) middle span, and (c) third span.

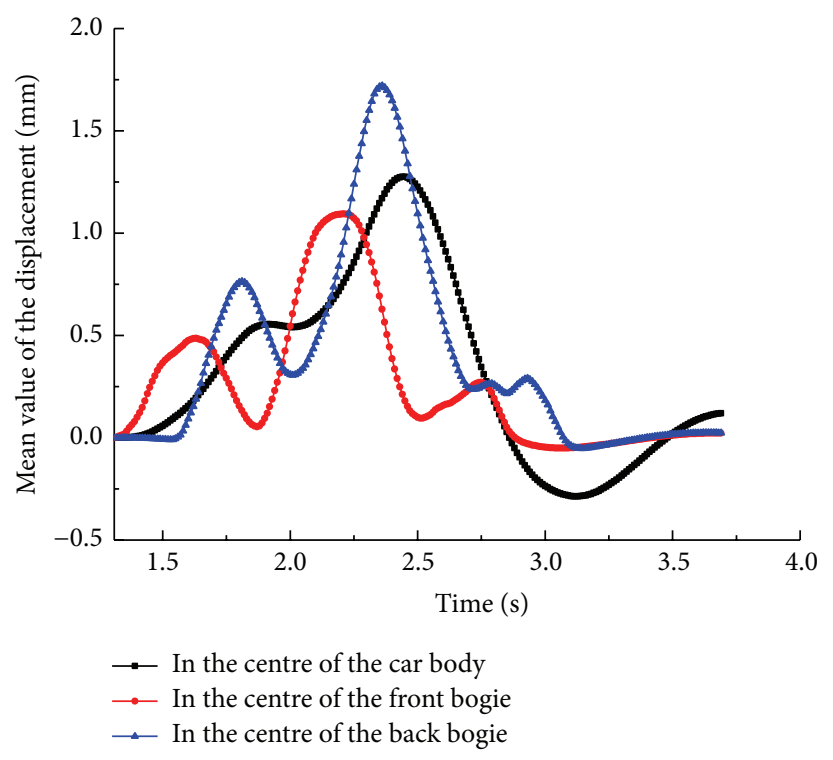

(a)

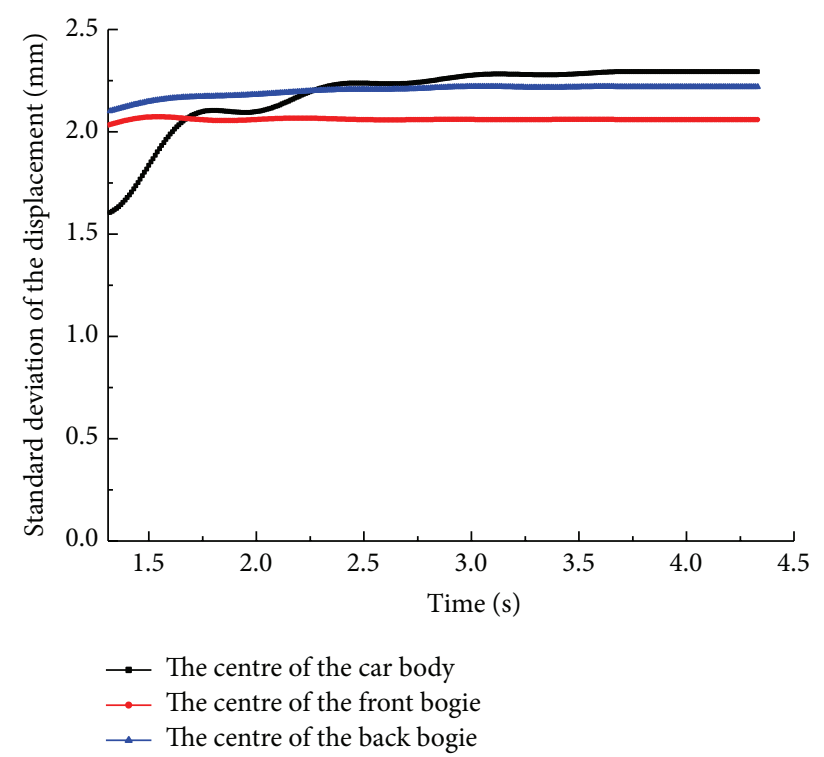

(b)

Figure 14: Displacement of the first railway car. (a) Mean value. (b) Standard deviation. 


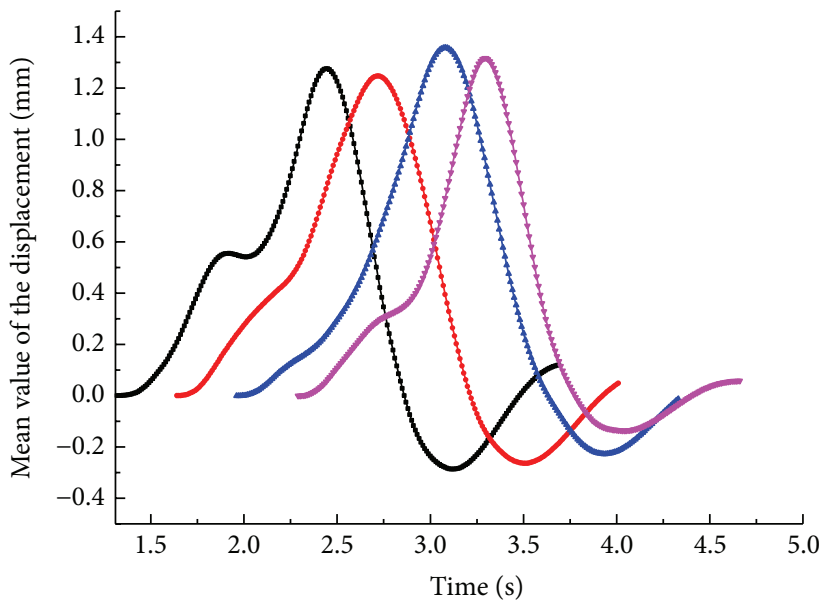

$\rightarrow$ In the centre of the first car body

- In the centre of the second car body

$\ldots$ In the centre of the third car body

$\rightarrow$ In the centre of the fourth car body

(a)

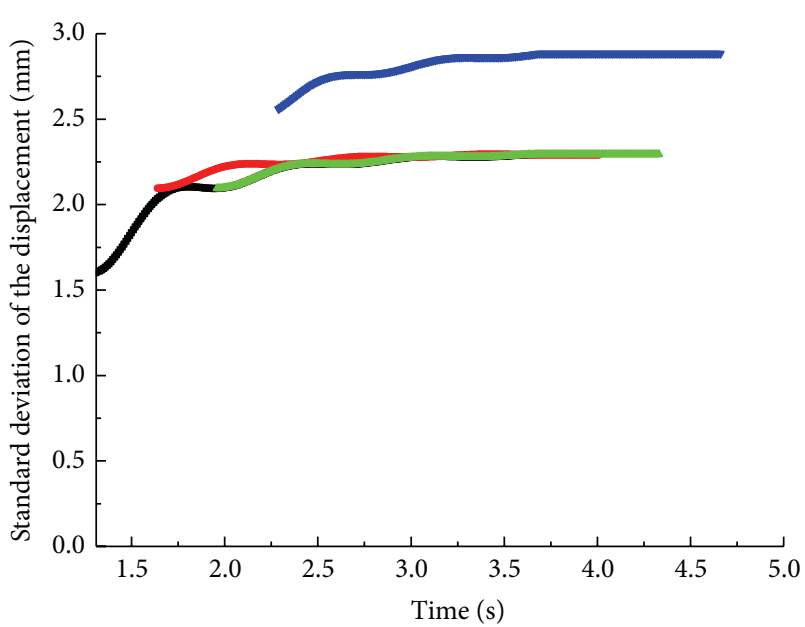

$\rightarrow$ The first car body $\quad \longrightarrow$ The third car body

$\rightarrow$ The second car body $\rightarrow$ The fourth car body

(b)

FIGURE 15: Displacement of the car bodies. (a) Mean value. (b) Standard deviation.
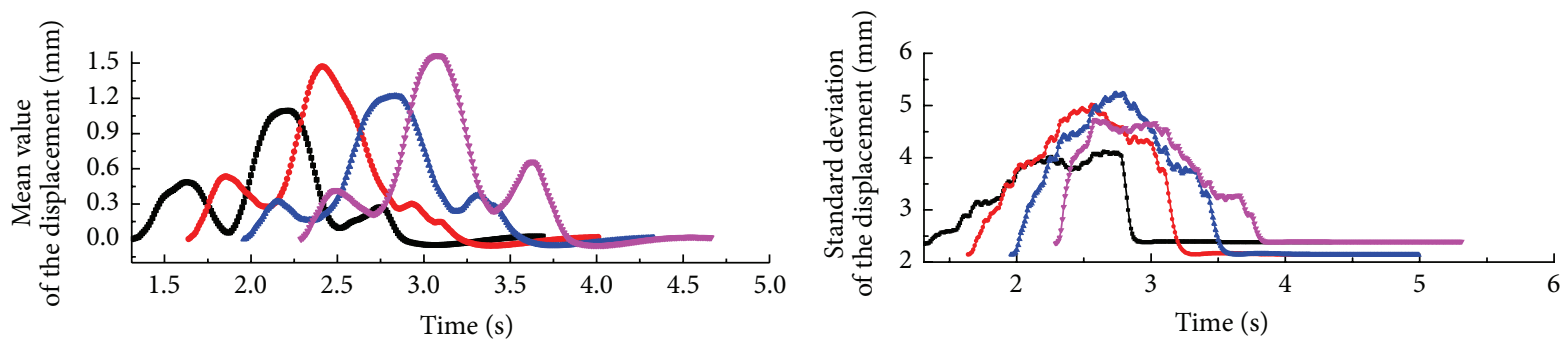

$\rightarrow$ In the centre of the first front bogie

- In the centre of the second front bogie

$\rightarrow$ In the centre of the third front bogie

$\longrightarrow$ In the centre of the fourth front bogie

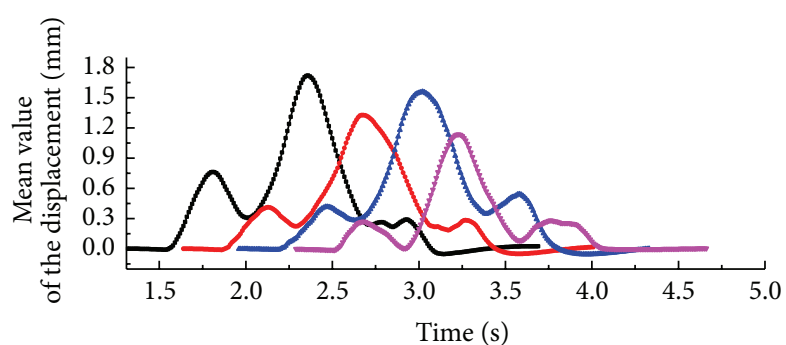

$\longrightarrow$ In the centre of the first back bogie

$\ldots$ In the centre of the second back bogie

$\ldots$ In the centre of the third back bogie

$\rightarrow$ In the centre of the fourth back bogie

(a)

$\longrightarrow$ In the centre of the first front bogie

- In the centre of the second front bogie

$\rightarrow$ In the centre of the third front bogie

$\longrightarrow$ In the centre of the fourth front bogie

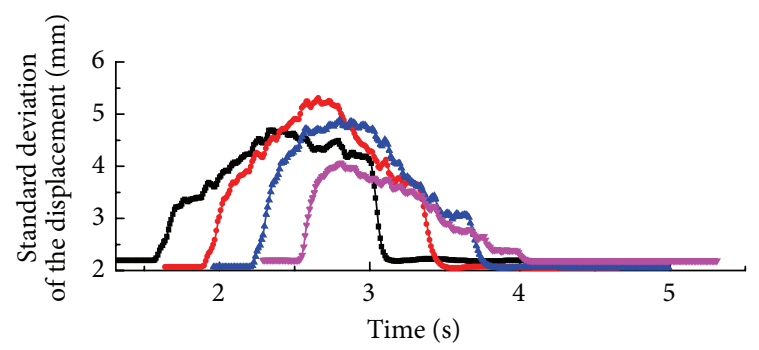

$\rightarrow$ In the centre of the first back bogie

$\rightarrow$ In the centre of the second back bogie

— In the centre of the third back bogie

$\rightarrow$ In the centre of the fourth back bogie

(b)

Figure 16: Displacement of the bogies. (a) Mean value. (b) Standard deviation. 

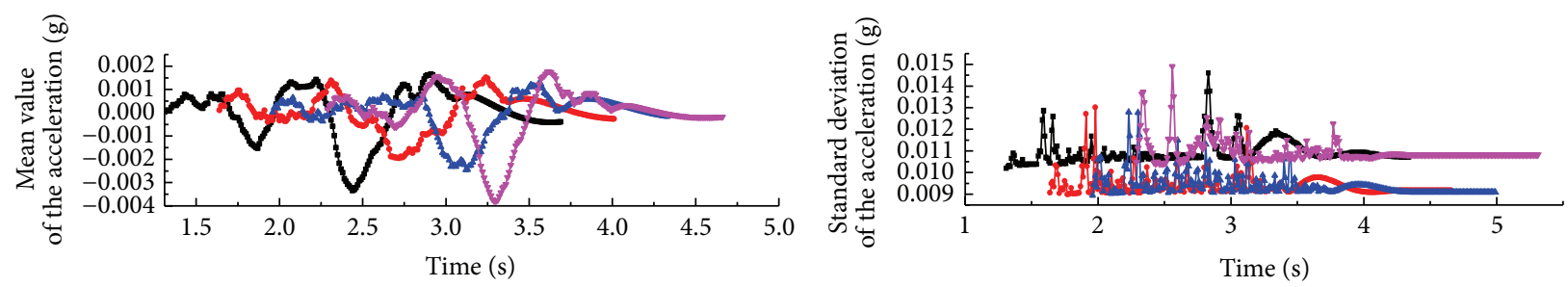

$\longrightarrow$ In the centre of the first car body
$\because$ In the centre of the second car body
$\square$ In the centre of the third car body
$\square$ In the centre of the fourth car body

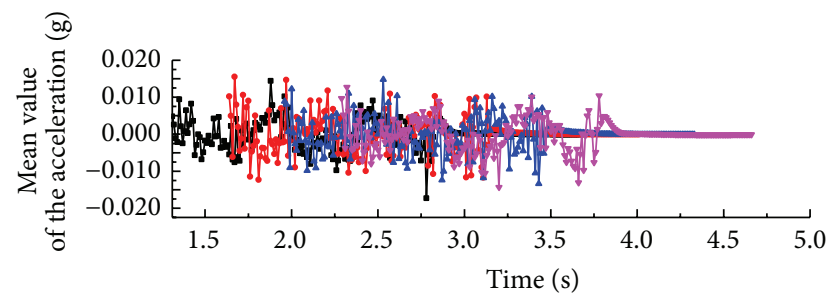

$\rightarrow$ In the centre of the first front bogie

- In the centre of the second front bogie

$\ldots$ In the centre of the third front bogie

- In the centre of the fourth front bogie

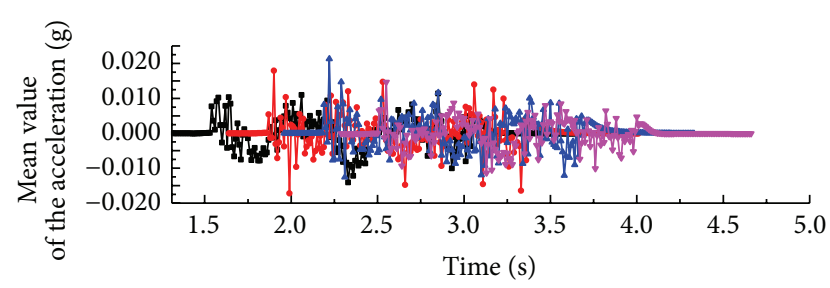

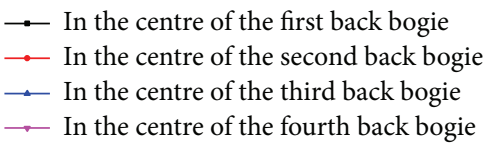

(a)
- In the centre of the first car body

$\ldots$ In the centre of the second car body

$\therefore$ In the centre of the third car body

$\rightarrow$ In the centre of the fourth car body

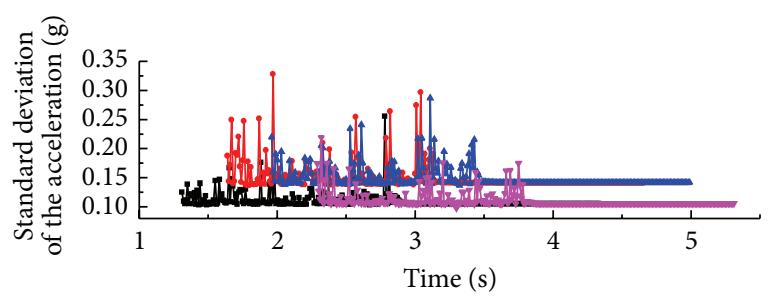

$\longrightarrow$ In the centre of the first front bogie

- In the centre of the second front bogie

$\rightarrow$ In the centre of the third front bogie

- In the centre of the fourth front bogie

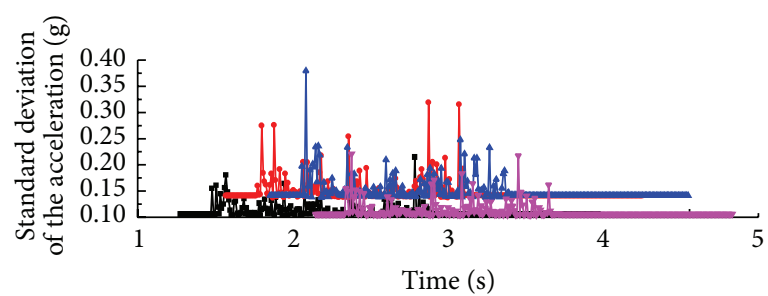

- In the centre of the first back bogie

$\rightarrow$ In the centre of the second back bogie

$\ldots$ In the centre of the third back bogie

$\rightarrow$ In the centre of the fourth back bogie

(b)

Figure 17: Acceleration of the vehicles. (a) Mean value. (b) Standard deviation.

the displacement of the two bogies vary with time in the same pattern but the values of the front bogie are smaller.

The mean and SD of the displacement as to the four car bodies vary with time in almost the same pattern. When all the four railway cars are on the bridge deck and the third vehicle passes around 0.4 times of the middle span length, the SD of the displacement about the car bodies reach their maximum value (Figure 15). Table 2 gives the position information where each vehicle is the SD of the displacement about the car body reaching its maximum.

Figures 16 and 17 show the mean and the standard deviation of the dynamic responses of the bogies varying with time in a similar pattern, but with different peak value and corresponding different position on the deck. The mean and the SD of the acceleration about the car bodies are smaller than the bogies.

As shown in Figure 18, at every frequency point, the PSDs of number 1 railway car vary with time when the vehicle
TABLE 2: Position corresponding to the maximum SD values.

\begin{tabular}{lc}
\hline Vehicle number & Position of the vehicle \\
\hline 1 & 0.6 times of the middle span length \\
2 & 0.6 times of the middle span length \\
3 & 0.4 times of the middle span length \\
4 & 0.1 times of the middle span length \\
\hline
\end{tabular}

Note: the distance is counted from the starting point of the middle span.

passes through the bridge in the beginning; then the values are close to stationary. The PSD values decrease with the frequency when the time is fixed, shown in Figure 18(a). We can see the same varying pattern in the values of PSD about the other three railway cars as shown in Figures 18(b), 18(c), and 18(d). The PSD of the displacement of the bogies and the PSD of the acceleration of the vehicles have similar varying pattern to the PSD of the displacement of the car bodies. 


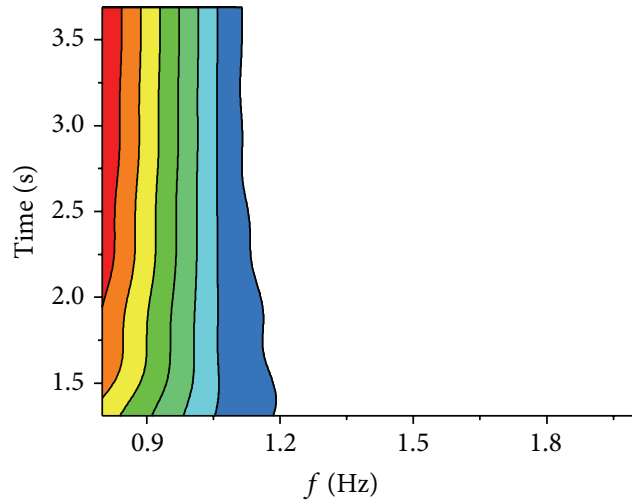

(a)

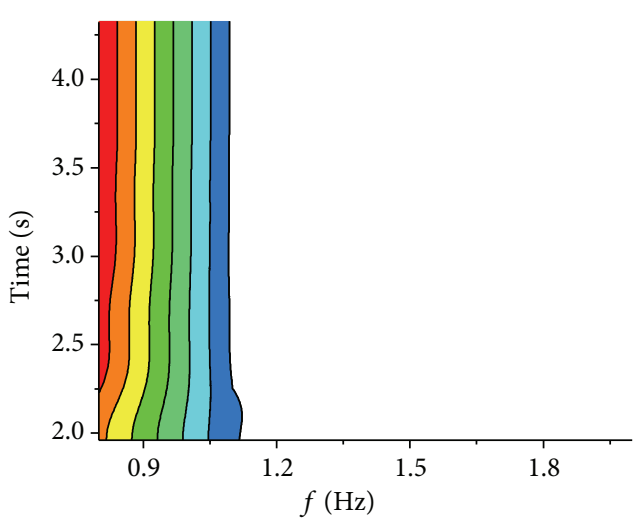

(c)
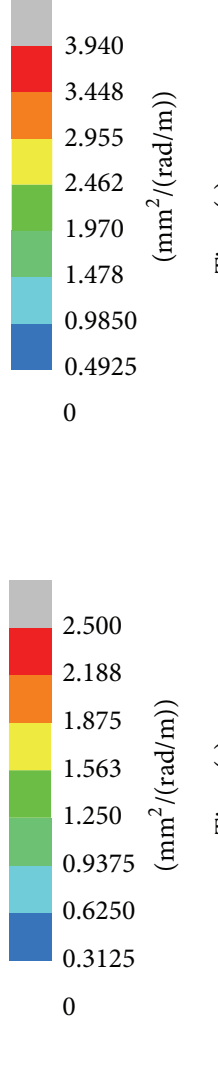

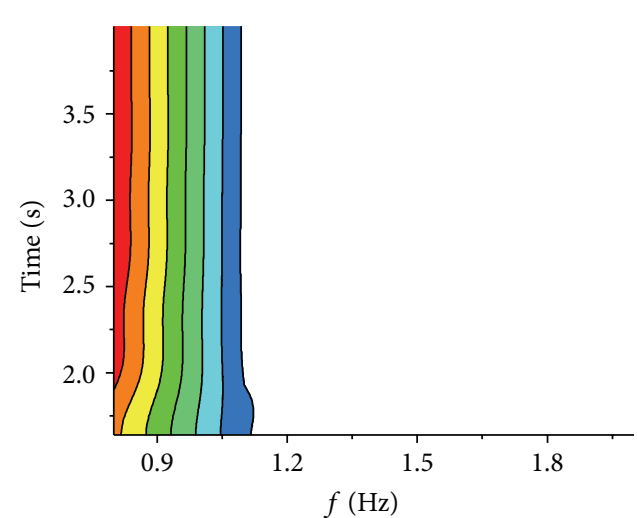

(b)

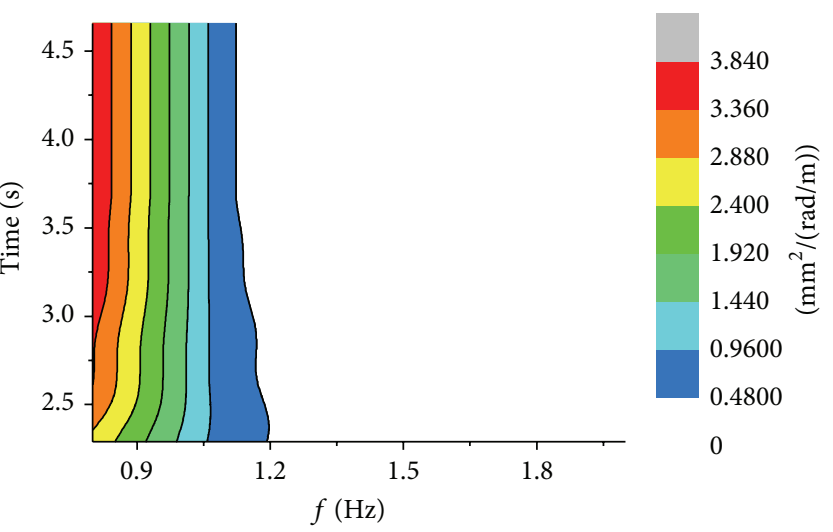

(d)

FIGURE 18: PSD of the displacement of the car bodies in the centre of the (a) first car body, (b) second car body, (c) third car body, and (d) fourth car body.

TABLE 3: Sperling index of the vehicles.

\begin{tabular}{lcccc}
\hline \multirow{2}{*}{ Vehicle number } & \multicolumn{2}{c}{ Car body } & \multicolumn{2}{c}{ Bogie } \\
& Mean & SD & Mean & SD \\
\hline 1 & 0.751 & 0.858 & 1.081 & 1.763 \\
2 & 0.655 & 0.823 & 1.014 & 1.948 \\
3 & 0.659 & 0.823 & 1.033 & 1.938 \\
4 & 0.682 & 0.869 & 1.014 & 1.795 \\
\hline
\end{tabular}

8.3. Discussion of the Safety and Riding Quality of the Railway Cars. As for the vertical wheel/rail force of the first railway car, the mean values of four wheelsets are around their static wheel load, that is, $156.8 \mathrm{kN}$ (motor car) or $143.08 \mathrm{kN}$ (trail car). As shown in Figures 19(a) and 19(b), we find that the vertical wheel/rail force is affected by the static wheel load. The mean and the SD of the wheel load reduction rate are very small and slightly vary with time as shown in Figures 19(c) and 19(d). We also find that the wheel load reduction rate is affected by the static wheel load from Figures 19(c) and 19(d).

As shown in Table 3, the mean value and the standard deviation of the vertical Sperling index of the car body are smaller than those of the bogie, owing to the dynamic loads not being exerted directly on the car body. The Sperling index has high-level dispersal, because its mean value is smaller than its SD.

\section{Conclusions}

Random vibration analysis of train-bridge coupling system is implemented by extending the pseudo excitation method (PEM). Expressions of the mean value, standard deviation, and power spectral density of the nonstationary random dynamic responses of bridge and vehicles are derived. Evaluation indicators for assessing the safety and riding quality of the railway cars are developed. Results produced by the redeveloped PEM agree with those generated by the MonteCarlo simulation method, but the presented method requires less computational efforts.

By taking a high-railway bridge with three-span continuous beam as a case study, the whole histories of an ICE3 train running on the bridge subjected to vertical random rail irregularity are investigated. The following observations and conclusions may be drawn from the present numerical study:

(1) The location of vehicle affects the bridge responses. 

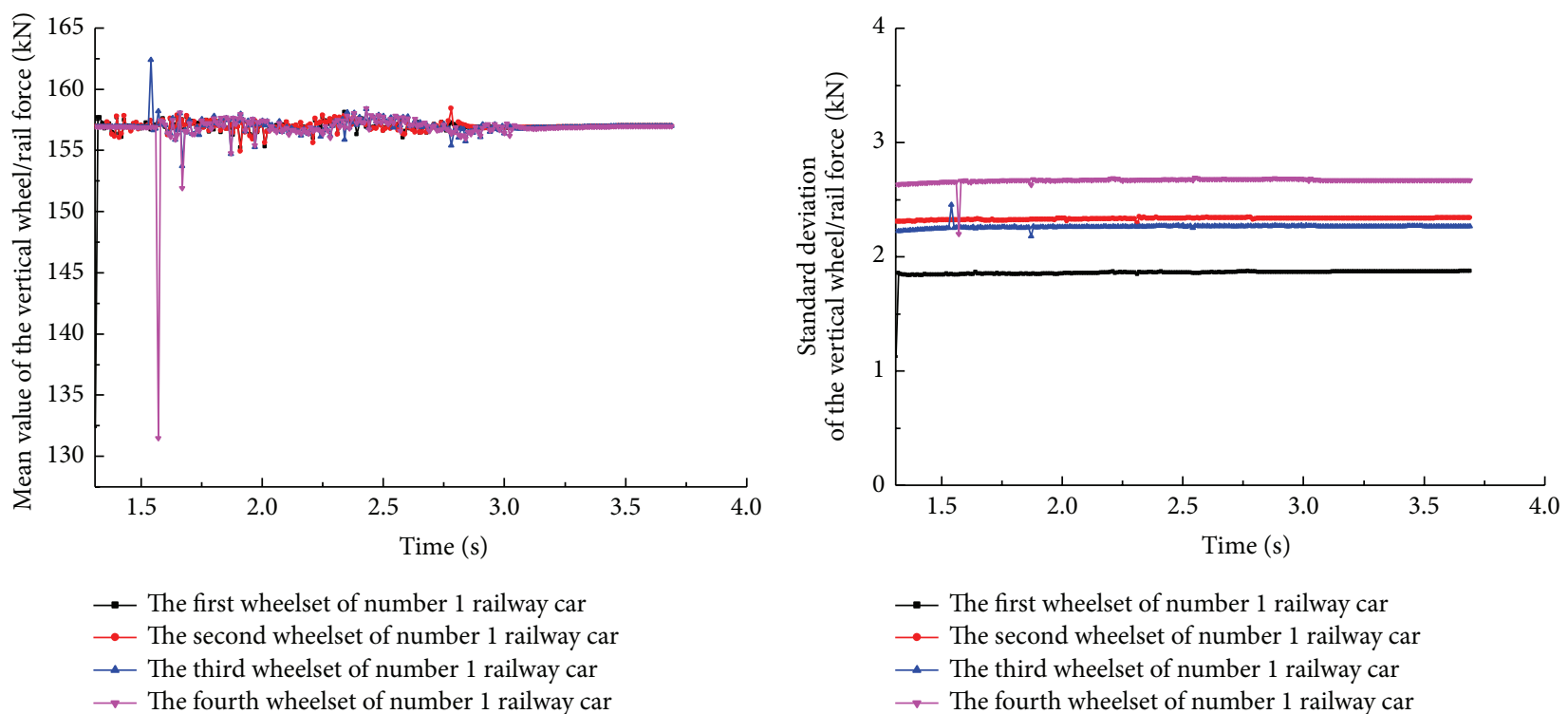

- The first wheelset of number 1 railway car

- - The second wheelset of number 1 railway car

—- The third wheelset of number 1 railway car

$\rightarrow$ The fourth wheelset of number 1 railway car

(a)

(b)
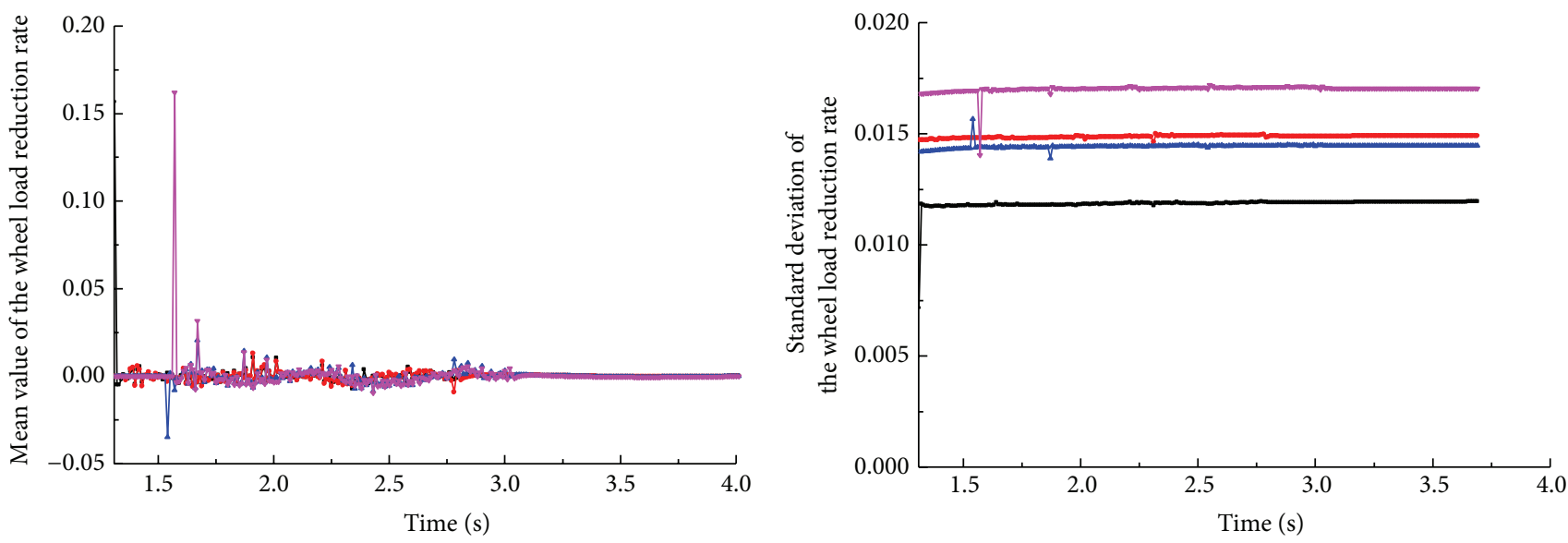

- The first wheelset of number 1 railway car

$\rightarrow$ The second wheelset of number 1 railway car

- The third wheelset of number 1 railway car

$\rightarrow$ The fourth wheelset of number 1 railway car

(c)

- The first wheelset of number 1 railway car

$\rightarrow$ The second wheelset of number 1 railway car

- The third wheelset of number 1 railway car

$\rightarrow$ The fourth wheelset of number 1 railway car

(d)

FIGURE 19: Vertical force and wheel load reduction rate as for number 1 railway car. (a) Mean value of the vertical wheel/rail force. (b) SD of the vertical wheel/rail force. (c) Mean value of the wheel load reduction rate. (d) SD of the wheel load reduction rate.

(2) The randomness of the dynamic responses of the midpoint in the middle span is different from that in the side span. The vertical displacement of the midpoint is mainly affected by the certain load, that is, the wheel load.

(3) Nonstationary features can be found from the PSD of the responses of the bridge.

(4) Randomness exists in the dynamic responses of the vehicles.
(5) The value of the vertical wheel/rail force and wheel load reduction is mainly affected by the static wheel load.

(6) The mean value and the standard deviation of the vertical Sperling index of the car body are smaller than those of the bogie due to the vibration suppression caused by the bogie. The Sperling index has high-level dispersal, which should be considered in the analysis and design of the coupling system.

Random analysis of train-bridge coupling system with rail irregularities is a very complex problem, which is related to 
the simulation of the random process, the implementation of the theory of random vibration on the time-varying coupling system, efficiency of the solution in the actual engineering application, and so on. In this paper, only a preliminary study on train-bridge coupling system with vertical rail irregularity is performed and illustrated by a case study. The algorithm presented in this paper and conclusions from the numerical example may be used as some reference for the dynamic design of the continuous beam bridge.

\section{Conflict of Interests}

The authors declare that there is no conflict of interests regarding the publication of this paper.

\section{Acknowledgments}

This research was supported by the National Natural Science Foundation of China (Grant no. 51308470), Fundamental Research Funds for the Central Universities (Grant no. SWJTU12CX062), and Australian Research Council through Discovery Projects.

\section{References}

[1] R. Willis, Appendix to the Report of the Commissioners Appointed to Inquire into the Application of Iron to Railway Structures, H.M. Stationary Office, London, UK, 1849.

[2] L. Frýba, "Effect of a force moving at variable speed along a beam," Acta Technica CSAV, vol. 18, no. 1, pp. 54-68, 1973.

[3] L. Frýba, Dynamics of Railway Bridges, Telfor, London, UK, 2nd edition, 1996.

[4] L. Frýba, Vibration of Solids and Structures under Moving Loads, Thomas Telford, 3rd edition, 1999.

[5] C. H. Lee, M. Kawatani, C. W. Kim, N. Nishimura, and Y. Kobayashi, "Dynamic response of a monorail steel bridge under a moving train," Journal of Sound and Vibration, vol. 294, no. 3, pp. 562-579, 2006.

[6] J. W. Kwark, E. S. Choi, Y. J. Kim, B. S. Kim, and S. I. Kim, "Dynamic behavior of two-span continuous concrete bridges under moving high-speed train," Computers and Structures, vol. 82, no. 4-5, pp. 463-474, 2004.

[7] W. Lacarbonara and V. Colone, "Dynamic response of arch bridges traversed by high-speed trains," Journal of Sound and Vibration, vol. 304, no. 1-2, pp. 72-90, 2007.

[8] C. H. Lee, C. W. Kim, M. Kawatani, N. Nishimura, and T. Kamizono, "Dynamic response analysis of monorail bridges under moving trains and riding comfort of trains," Engineering Structures, vol. 27, no. 14, pp. 1999-2013, 2005.

[9] Y. L. Xu, N. Zhang, and H. Xia, "Vibration of coupled train and cable-stayed bridge systems in cross winds," Engineering Structures, vol. 26, no. 10, pp. 1389-1406, 2004.

[10] Y. B. Yang, C. L. Lin, J. D. Yau, and D. W. Chang, "Mechanism of resonance and cancellation for train-induced vibrations on bridges with elastic bearings," Journal of Sound and Vibration, vol. 269, no. 1-2, pp. 345-360, 2004.
[11] Y. B. Yang, K. C. Chang, and Y. C. Li, "Filtering techniques for extracting bridge frequencies from a test vehicle moving over the bridge," Engineering Structures, vol. 48, pp. 353-362, 2013.

[12] Y.-B. Yang and Y.-S. Wu, "A versatile element for analyzing vehicle-bridge interaction response," Engineering Structures, vol. 23, no. 5, pp. 452-469, 2001.

[13] H. Zeng and C. W. Bert, "Dynamic amplification of bridge/vehicle interaction: a parametric study for a skewed bridge," International Journal of Structural Stability and Dynamics, vol. 3, no. 1, pp. 71-90, 2003.

[14] C. Xia, H. Xia, N. Zhang, and W. Guo, "Effect of truck collision on dynamic response of train-bridge systems and running safety of high-speed trains," International Journal of Structural Stability and Dynamics, vol. 13, no. 3, Article ID 1250064, 2013.

[15] S.-I. Kim and N.-S. Kim, "Dynamic performances of a railway bridge under moving train load using experimental modal parameters," International Journal of Structural Stability and Dynamics, vol. 10, no. 1, pp. 91-109, 2010.

[16] L. Frýba, "Non-stationary response of a beam to a moving random force," Journal of Sound and Vibration, vol. 46, no. 3, pp. 323-338, 1976.

[17] A. Garinei and G. Risitano, "Vibrations of railway bridges for high speed trains under moving loads varying in time," Engineering Structures, vol. 30, no. 3, pp. 724-732, 2008.

[18] G. Ricciardi, "Random vibration of beam under moving loads," Journal of Engineering Mechanics, vol. 120, no. 11, pp. 2361-2378, 1994.

[19] F. T. K. Au, J. J. Wang, and Y. K. Cheung, "Impact study of cable-stayed railway bridges with random rail irregularities," Engineering Structures, vol. 24, no. 5, pp. 529-541, 2002.

[20] H. Xia, G. De Roeck, H. R. Zhang, and N. Zhang, "Dynamic analysis of train-bridge system and its application in steel girder reinforcement," Computers and Structures, vol. 79, no. 20-21, pp. 1851-1860, 2001.

[21] H. Xia and N. Zhang, Dynamic Interaction of Vehicles and structures, Science Press, Beijing, China, 2005.

[22] M. Majka and M. Hartnett, "Dynamic response of bridges to moving trains: a study on effects of random track irregularities and bridge skewness," Computers \& Structures, vol. 87, no. 19-20, pp. 1233-1252, 2009.

[23] Z. B. Jin, Train-track-bridge system and train-bridge stochastic vibration [Ph.D. thesis], Southwest Jiaotong University, 2007.

[24] J. H. Lin, W. Shen, and F. W. Williams, "Accurate high-speed computation of non-stationary random structural response," Engineering Structures, vol. 19, no. 7, pp. 586-593, 1997.

[25] Z. C. Zhang, J. H. Lin, Y. H. Zhang, W. P. Howson, and F. W. Williams, "Non-stationary random vibration analysis of threedimensional train-bridge systems," Vehicle System Dynamics, vol. 48, no. 4, pp. 457-480, 2010.

[26] V. De Salvo, G. Muscolino, and A. Palmeri, "A substructure approach tailored to the dynamic analysis of multi-span continuous beams under moving loads," Journal of Sound and Vibration, vol. 329, no. 15, pp. 3101-3120, 2010.

[27] D. Mu and D.-H. Choi, "Dynamic responses of a continuous beam railway bridge under moving high speed train with random track irregularity," International Journal of Steel Structures, vol. 14, no. 4, pp. 797-810, 2014.

[28] Y. Zhu, Train-bridge coupling system stochastic theory and application [Ph.D. thesis], Southwest Jiaotong University, 2011.

[29] J. H. Lin and Y. H. Zhang, Pseudo Excitation Method in Random Vibration, Science Press, Beijing, China, 2006. 
[30] J. Lin, Y. Zhao, and Y. Zhang, "Accurate and highly efficient algorithms for structural stationary/non-stationary random responses," Computer Methods in Applied Mechanics and Engineering, vol. 191, no. 1-2, pp. 103-111, 2001.

[31] W. M. Zhai, Vehicle-Track Coupling Dynamic, Science Press, Beijing, China, 2007. 


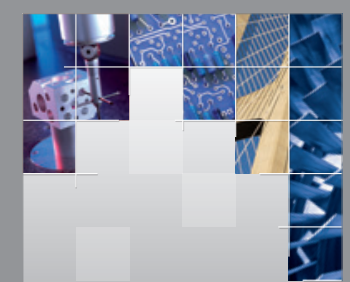

\section{Enfincering}
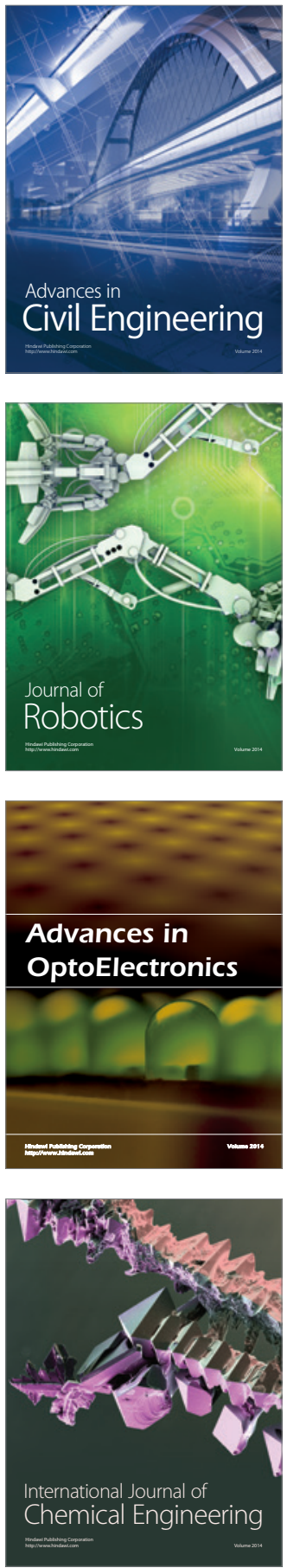

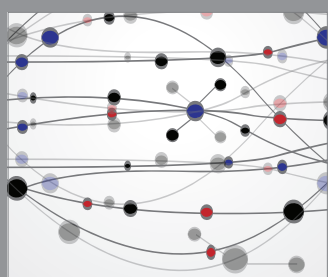

The Scientific World Journal

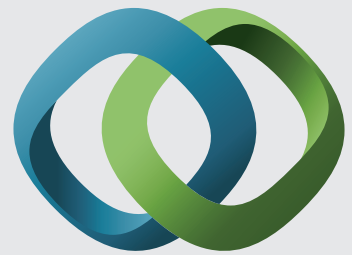

\section{Hindawi}

Submit your manuscripts at

http://www.hindawi.com
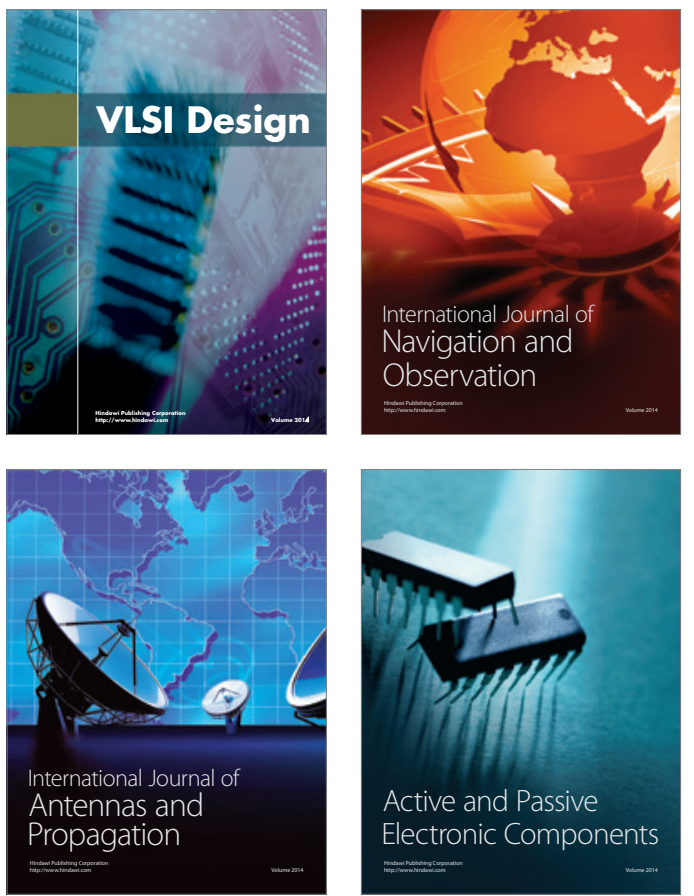
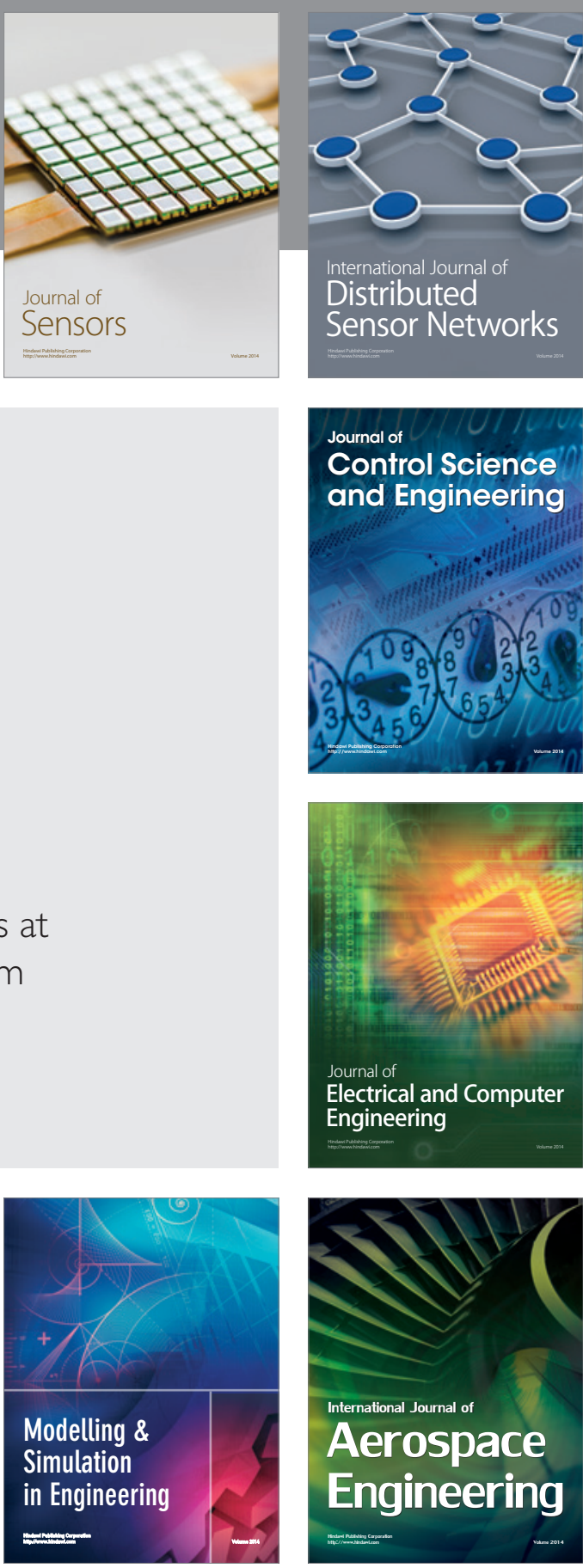

International Journal of

Distributed

Sensor Networks

Journal of

Control Science

and Engineering
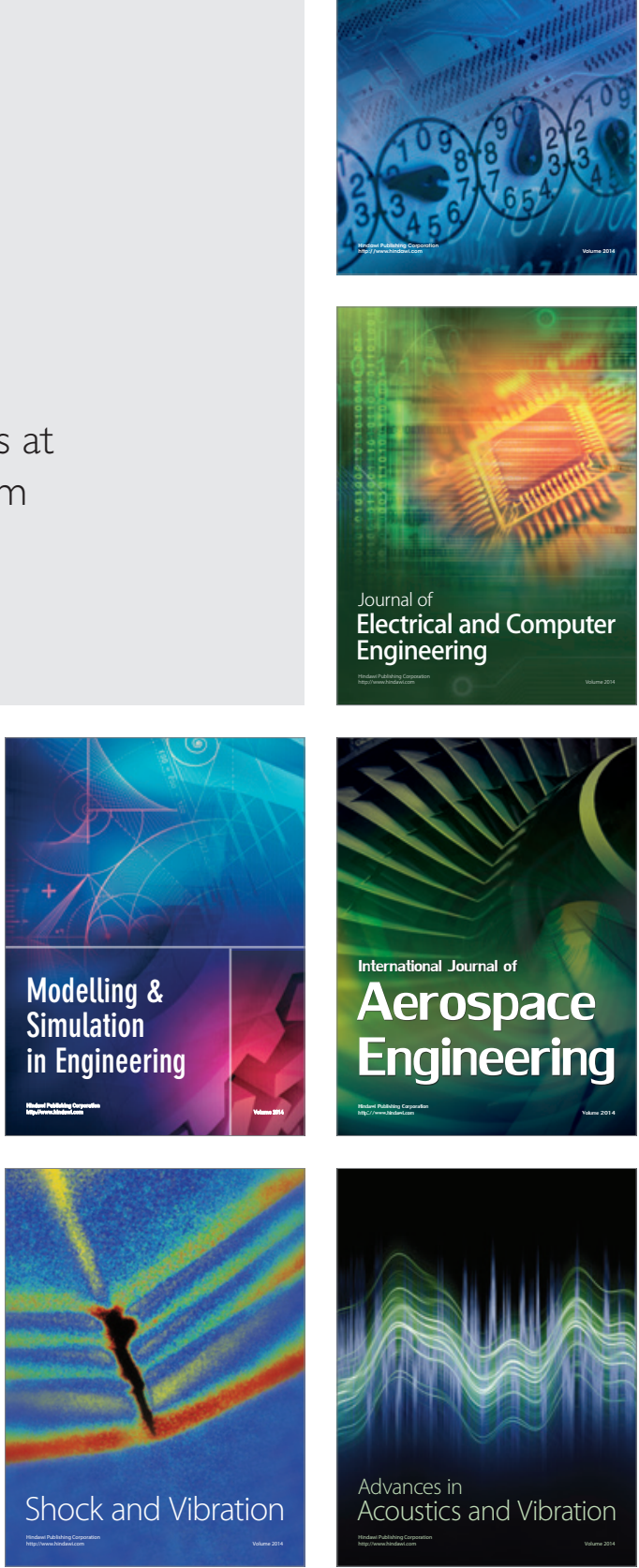